\title{
Botanical Drugs and Supplements Affecting the Immune Response in the Time of COVID-19: Implications for Research and Clinical Practice
}

Brendler $\mathrm{T}^{1,2^{*}}$, Al-Harrasi $\mathrm{A}^{3}$, Bauer $\mathrm{R}^{4}$, Gafner $\mathrm{S}^{5}$, Hardy $\mathrm{ML}^{6}$, Heinrich $\mathrm{M}^{7,8}$, Hosseinzadeh $\mathrm{H}^{9,10}$, Izzo $\mathrm{AA}^{11}$, Michaelis M12, Nassiri-Asl M13,14, Panossian A15,16, Wasser $\mathrm{S}^{17}$, Williamson EM18

1 Department of Botany and Plant Biotechnology, University of Johannesburg, South Africa

2 Plantaphile, Collingswood NJ, USA

${ }^{3}$ Natural and Medical Sciences Research Centre, University of Nizwa, Nizwa 616, Sultanate of Oman

4 Institute of Pharmaceutical Sciences, Department of Pharmacognosy, University of Graz, Austria

5 American Botanical Council, Austin TX, USA

${ }^{6}$ Association of Integrative and Holistic Medicine, San Diego CA, USA

7 Research Group 'Pharmacognosy and Phytotherapy', UCL School of Pharmacy, University of London, UK

${ }^{8}$ Graduate Institute of Integrated Medicine, College of Chinese Medicine, China Medical University, Taichung, Taiwan

${ }^{7}$ Pharmaceutical Research Center, Pharmaceutical Technology Institute, Mashhad University of Medical Sciences, Mashhad, Iran

${ }^{9}$ Department of Pharmacodynamics and Toxicology, School of Pharmacy, Mashhad University of Medical Sciences, Mashhad, Iran

11 Department of Pharmacy, School of Medicine, University of Naples Federico II, Naples, Italy

12 Industrial Biotechnology Centre and School of Biosciences, University of Kent, Canterbury, UK

13 Department of Pharmacology, School of Medicine, Shahid Beheshti University of Medical Sciences, Tehran, Iran

14 Neurobiology Research Center, Shahid Beheshti University of Medical Sciences, Tehran, Iran

15 Phytomed AB, Vaxtorp, Halland, Sweden

16 Europharma USA Inc., Green Bay, WI, USA

17 Institute of Evolution \& Department of Evolutionary and Environmental Biology, University of Haifa, Israel

18 University of Reading, School of Pharmacy, Whiteknights, Reading, UK

* corresponding author: txb@plantaphile.eu

\section{Abstract}

In times of health crisis, including the current COVID-19 pandemic, the potential benefit of botanical drugs and supplements emerges as a focus of attention, although controversial efficacy claims are rightly a concern. Phytotherapy has an established role in everyday selfcare and health care, but since botanical preparations contain many chemical constituents rather than single compounds, challenges arise in demonstrating efficacy and safety. However, there is ample traditional, empirical, and clinical evidence that botanicals can offer some protection and alleviation of disease symptoms as well as promoting general well-being. Newly emerging viral infections, specifically COVID-19, represent a unique challenge in their novelty and absence of established antiviral treatment or immunization. We discuss here the roles and limitations of phytotherapy in helping to prevent and address viral infections, and specifically regarding their effects on immune response. Botanicals with a documented immunomodulatory, immunostimulatory, and antiinflammatory effect include adaptogens, Boswellia spp., Curcuma longa, Echinacea spp., Glycyrrhiza spp., medicinal fungi, Pelargonium sidoides, salicylate-yielding herbs, and Sambucus spp. We further provide a clinical perspective on applications and safety of these herbs in prevention, onset, progression, and convalescence from respiratory viral infections.

Keywords: adaptogens, Boswellia, herbal medicine, COVID-19, Curcuma, Echinacea, Glycyrrhiza, medicinal fungi, Pelargonium, phytotherapy, salicylate, Sambucus

\section{Introduction}

In December 2019, a novel beta-coronavirus identified in China, was found to cause respiratory disease and pneumonia (Zhu et al., 2020). The infection developed quickly into a pandemic involving every continent except Antarctica, with over 73 million cases and 1.6 million deaths reported globally (16 December 2020) (https://covid19.who.int/; Zhu et al., 2020). The virus was initially referred to as novel coronavirus 2019 (nCoV-2019), but is now called severe acute respiratory syndrome coronavirus 2 (SARS-CoV-2) 
(Coronaviridae Study Group of the International Committee on Taxonomy of, 2020) causing Coronavirus disease 2019 (COVID-19) (https://covid19.who.int/).

The complexity of the disease suggests potential need for a range of therapies, including antiviral agents, immunostimulants, immunosuppressants, and anticoagulants (Al-Horani, Kar, \& Aliter, 2020; Drozdzal et al., 2020; Fierabracci, Arena, \& Rossi, 2020; Schijns \& Lavelle, 2020; Sethi \& Bach, 2020; van Haren et al., 2020). Although basic scientific information regarding the virus has accumulated quickly over the past year, no definitive cure is available and approved drugs such (as the antiviral drug remdesivir and the corticosteroid dexamethasone show only moderate benefit (Beigel et al., 2020; Horby et al., 2020; https://covid19.who.int/). Vaccines are now receiving regulatory approvals but will take time to reach the general public.

Sepsis, cardiovascular, and/or respiratory diseases are among the most serious complications in COVID-19 patients, especially the elderly and those with underlying health problems (F. Zhou et al., 2020). Use of NSAIDs for COVID-19 patients has been a matter of debate (Little, 2020), but strong evidence is lacking to advise against their use. Some reports indicate the harm of NSAIDs including ibuprofen, naproxen, and diclofenac due to their relationship with high rates of cardiovascular diseases, including myocardial infarction, heart failure, and stroke (Bhala et al., 2013). However, other reports support their intermittent use if paracetamol (acetaminophen) proved insufficient (Besedovsky, Lange, \& Haack, 2019; Ye, Wang, \& Mao, 2020).

Botanical drugs and supplements have been recommended for prevention (Boozari \& Hosseinzadeh, 2020), as adjuvant therapy (Silveira et al., 2020), or after exposure to SARS-CoV-2 (Ang, Lee, Kim, \& Lee, 2020). Traditional Chinese Herbal Medicine (TCM) is used in conjunction with conventional Western medicine to reportedly good effect (Fan, Gu, \& Alemi, 2020). Natural extracts and compounds of potential clinical interest have been identified based on observed mechanisms of action and in-silico studies, but no clinical studies have yet been performed (Fuzimoto \& Isidoro, 2020; Zhang, Wu, Zhang, Deng, \& Peng, 2020).

Concerns over use of botanical drugs and supplements include being 'unproven', with insufficient evidence to endorse widespread use (Y. Yang, 2020), and the theoretical possibility that immune-stimulating herbs' may initiate a cytokine storm (Alschuler et al., 2020). There is an urgent need for authoritative information. This review addresses misapprehensions regarding the safety and efficacy of herbal ingredients, to highlight research targets and to guide clinical use.

\section{SARS-CoV-2 and Immune Response to Infection}

SARS-CoV-2 is the seventh coronavirus known to infect and cause disease in humans, alongside human coronaviruses 229E (HCoV-229E, alphacoronavirus), OC43 (HCoV-OC43, betacoronavirus), NL63 (HCoVNL63, New Haven, (alphacoronavirus), HKU1 (HCoV-HKU1, betacoronavirus), SARS-CoV (betacoronavirus), and Middle East respiratory syndrome coronavirus (MERS-CoV, betacoronavirus) (Corman, Muth, Niemeyer, \& Drosten, 2018; Cui, Li, \& Shi, 2019; F. Wu et al., 2020; Yin \& Wunderink, 2018). HCoV-229E, HCoV-OC43, HCoV-NL63, and HCoV-HKU1 are endemic in humans and typically cause mild-to-moderate common coldlike respiratory disease (Channappanavar \& Perlman, 2017; Corman et al., 2018).

Since 2002, SARS-CoV-2 is the third coronavirus causing a substantial outbreak associated with significant mortality (F. Wu et al., 2020). SARS-CoV outbreak in 2002/2003 resulted in 8,098 confirmed and suspected cases and 774 deaths (mortality rate: 9.6\%) (https://www.who.int/publications/m/item/summary-ofprobable-sars-cases-with-onset-of-illness-from-1-november-2002-to-31-july-2003). For MERS-CoV, WHO reports 2,562 laboratory-confirmed cases and 881 deaths (mortality rate: 34.4\%) (https://www.who.int/emergencies/mers-cov/en/). However, human-to-human spread of MERS-CoV remains very limited. SARS-CoV-2 disease is associated with a mortality rate below 1\% (Gudbjartsson et al., 2020; Perez-Saez et al., 2020; Poletti et al., 2020). Unlike SARS-CoV, SARS-CoV-2 can be transmitted by asymptomatic individuals (S. Lee, Meyler, Mozel, Tauh, \& Merchant, 2020; Petersen et al., 2020; Pollán et al., 2020). 
SARS-CoV-2 has a single-stranded positive sense RNA (+sSRNA) genome of approximately 29.8 kilobases and was annotated to contain 14 ORFs and 27 proteins (A. Wu et al., 2020). Two ORFs at the 5 '-terminus (ORF1a, ORF1ab) encode the polyproteins pp1a and pp1b, which comprise 15 non-structural proteins (NSPs), the NSPs 1 to 10 and 12-16 (A. Wu et al., 2020). Additionally, SARS-CoV-2 encodes four structural proteins (S, E, M, N) and eight accessory proteins (3a, 3b, p6, 7a, 7b, 8b, 9b, orf14) (A. Wu et al., 2020).

The spike (S) protein mediates coronavirus entry into host cells (Y. Chen, Liu, \& Guo, 2020; Cui et al., 2019). ACE2 has been identified as cellular receptors for SARS-CoV-2 S, the same receptors as for SARS-CoV (Cui et al., 2019; Hoffmann et al., 2020; Letko, Marzi, \& Munster, 2020; H. Zhou et al., 2020). To interact with ACE2, SARS-CoV-2 S requires cleavage by cellular serine proteases such as TMPRSS2 (Hoffmann et al., 2020; Shang et al., 2020). ACE2 is widely expressed in cells from multiple tissues (Ni et al., 2020). Accordingly, COVID-19 symptoms can range from mild respiratory to life-threatening multi-organ disease.

The immune system is a complex network, uniting cells, tissues and organs with biochemical processes and interactions, aimed at maintaining the integrity and function of an organism exposed to environmental insults. When triggered by a specific provocation, the immune system exhibits a response. Immune responses can be grouped into two general types, innate and adaptive immunity, both of which contain humoral and cellular components. If a pathogen overcomes the physical barriers of the human body, (skin or mucous membranes) it is immediately addressed by the innate immune system, comprising physical epithelial barriers, phagocytic leukocytes, dendritic cells, natural killer (NK) cells, circulating plasma molecules (e.g., antimicrobial peptides, reactive oxygen species), the complement system, innate antibodies, and related cytokines. While rapid, innate immune responses are not specific to the type of microorganism, i.e., different provocations trigger similar reactions and response patterns. Thus, innate immunity does not provide continuous protection from a specific pathogen (Carrillo, García, Coronado, García, \& Cordero, 2017; D. H. Lee \& Kim, 2014; J. M. Wu et al., 2016).

The control of adaptive immunity by the innate immune system follows a well-established paradigm (S. P. Wasser, 2017; Zmitrovich, Belova, Balandaykin, Bondartseva, \& Wasser, 2019). Recognition of a pathogen by the innate immune system is mediated by pattern-recognition receptors (PRRs) detecting conserved pathogen-associated molecular patterns (PAMPs). These molecular patterns may represent viral nucleic acids, bacterial or fungal cell-wall components. There are several families of PRRs, e.g., members of the Tolllike receptor (TLR), nuclear oligomerization domain (NOD) or NOD-like receptor, C-type lectin receptor, complement receptor, and mannose receptor families (Coll \& O'Neill, 2010), which can detect foreign materials, e.g., polysaccharides, glycolipids, lipoproteins, nucleotides, and nucleic acids. When PRR identifies PAMP, it initiates inflammatory responses and innate host defences. While mechanisms underlying the sensing of microbial organisms by different PRR receptors are still being investigated, PRR-mediated sensing determines the origin of the antigen and type of infection, leading to the activation of adaptive immune responses (Zmitrovich et al., 2019).

Adaptive immune responses are slower to manifest, but highly specific to the triggering pathogen. There are two categories of adaptive immune responses - humoral immunity (mediated by antibodies produced by B lymphocytes) and cell-mediated immunity (mediated by T lymphocytes). The adaptive immune system can provide long-lasting protection from specific pathogens by creating immunological memory following an encounter and response, allowing for enhanced response to the same pathogen in the future (D. H. Lee \& Kim, 2014; J. M. Wu et al., 2016).

In an uncompromised immune system, the inflammatory response initiated by a viral infection is moderated and ultimately resolved following clearance of the presenting antigen. Inflammation early in infection facilitates the arousal of the immune response and assists the delivery of response cells to the site of infection. However, there is potential harm in unregulated inflammation and excess stimulatory cytokine production. Anti-inflammatory cytokines, e.g., Il-10, are released. regulating the pro-inflammatory response (Tay, Poh, Renia, MacAry, \& Ng, 2020). 
Severe COVID-19 disease appears driven by an excessive immune response and hyperinflammation ('cytokine storm'), resulting in acute respiratory distress syndrome (ARDS), systemic coagulation and thrombus formation (coagulopathy), and sepsis-related multiple-organ failure (Domingo et al., 2020; Iba, Levy, Levi, \& Thachil, 2020; Morris et al., 2020; Nowill \& de Campos-Lima, 2020). A broad range of proinflammatory cytokines has been associated with severe COVID-19 disease including IL-1b, IL-17, IFN- $\gamma$, TNF- $\alpha$ and IL-6. Elevated levels of IL-2, IL-7, IL-10, G-CSF, IP-10, MCP1, MIP1A, and TNF- $\alpha$ were found in COVID-19 patients, who required intensive care (Cao, 2020; Nowill \& de Campos-Lima, 2020), and IL-6 was found to be particularly high in patients who died from COVID-19 (Ruan, Yang, Wang, Jiang, \& Song, 2020).

\section{Echinacea (Echinacea spp.)}

Preparations made from aerial and root parts of various species of Echinacea (mainly E. angustifolia and $E$. purpurea) are popular self-medications for the prevention and treatment of the common cold.

Immunomodulatory effects on macrophages and NK cells have been demonstrated by echinacea extracts (Hudson, 2012; S. Park et al., 2018; Pleschka, Stein, Schoop, \& Hudson, 2009; Sharma, Anderson, Schoop, \& Hudson, 2009; Sharma, Arnason, \& Hudson, 2006), including decreasing the rhinovirus-induced expression of over 30 transcription factors essential to inflammatory cytokine production (Sharma et al., 2006). In human bronchial epithelial cells (BEAS-2B), echinacea inhibited induction of inflammatory cytokines and chemokines by a variety of respiratory viruses (Sharma et al., 2009). Echinacea protected against stressmediated immune suppression in BALB/c mice by increasing $\mathrm{CD}^{4+}$ and $\mathrm{CD}^{8+} \mathrm{T}$ lymphocytes, up-regulating cytokines and increasing NK cell activity (S. Park et al., 2018). Echinacea extracts contain a mixture of compounds with cytokine-suppressing, but also cytokine-inducing, effects (Todd et al., 2015). 8,11Dihydroxy-dodeca-2E,4E,9E-trienoic acid isobutylamide was found to suppress production of TNF- $\alpha$ by RAW 264.7 cells (Leyte-Lugo et al., 2015), suggesting that echinacea extracts and alkamides may be useful for treating allergic and inflammatory responses mediated by mast cells (Gulledge et al., 2018).

Extracts and alkamides from E. purpurea may alleviate the inflammatory response that accompanies infection with H1N1 influenza (Cech et al., 2010). Alkamides are readily bioavailable and bind to cannabinoid receptors (CB2R), which are key modulators of the immune system (Ardjomand-Woelkart \& Bauer, 2016). Selective stimulation of CB2R may reduce the inflammatory response in SARS-CoV-2 patients (Rossi, Tortora, Argenziano, Di Paola, \& Punzo, 2020). There are no commercially available CB2R agonists approved for human use (Rossi et al., 2020), although alkamides of echinacea have such an effect (Raduner et al., 2006; Woelkart \& Bauer, 2007). CB2 receptor stimulation has also a well-documented immunosuppressive effect by reducing immune cell proliferation (Rockwell, Raman, Kaplan, \& Kaminski, 2008), and production of antibodies (Carayon et al., 1998), which may be beneficial in the exacerbated inflammatory response in COVID-19 patients.

Echinacea extracts have shown direct antiviral effects in vitro, preventing binding and cell entry of highly pathogenic avian (H5N1, H7N7) and swine origin H1N1 influenza (Pleschka et al., 2009). Despite sequential passage in cell culture with H1N1 present, no resistance to the protective effects of echinacea were seen. In a recent in vitro study, a standardized preparation from fresh E. purpurea herb and root (Echinaforce $\AA$, A. Vogel, Switzerland) showed antiviral activity against human coronaviridae HCoV-229E, SARS-CoV-1, SARSCoV-2, and MERS-CoV upon direct contact (Signer et al., 2020).

Meta-analysis of human clinical trials has demonstrated efficacy for prevention and treatment of common cold viral infections (David \& Cunningham, 2019). A further meta-analysis, focused on recurrent upper respiratory tract infections, showed that ethanolic extracts of echinacea decreased risk of developing subsequent infections in the same cold season as well as lowering the risk of infectious complications (A. Schapowal, Klein, \& Johnston, 2015).

Analysis of the adverse events reported in multiple clinical trials do not show occurrence of serious adverse events (David \& Cunningham, 2019; A. Schapowal et al., 2015). The largest human echinacea trial involved $>700$ patients treated for four months; occurrence of adverse events was $9 \%$ in the treatment group and 
$10 \%$ in the placebo group (Jawad, Schoop, Suter, Klein, \& Eccles, 2012). Theoretical concerns that inflammatory symptoms of autoimmune diseases, and HIV infection may be exacerbated by immunostimulatory effects of echinacea, and that these may stimulate the onset of cytokine storm have been raised (Alschuler et al., 2020). Pharmacological data suggest that echinacea exerts a modulation of the immune response, balancing stimulatory and suppressive effects (Matthias, Banbury, Bone, Leach, \& Lehmann, 2008), resulting in a biphasic effect (Gertsch, Schoop, Kuenzle, \& Suter, 2004). A comprehensive review of the safety of echinacea preparations did not substantiate such a risk (Ardjomand-Woelkart \& Bauer, 2016). A low rate of acute hypersensitivity reactions in children ( $5 \%$ of almost 15,000 adverse event reports) using echinacea (Meincke et al., 2017).

Echinacea shows no significant inhibition of cytochrome P450 enzymes 2D6 or 1A2 and weak induction of 3AA4, with induction of the drug transporter p-glycoprotein (Ardjomand-Woelkart \& Bauer, 2016). Several adverse events have been reported with drugs with a narrow therapeutic index but the clinical evidence does not consistently demonstrate a significant effect (Fasinu \& Rapp, 2019). In general, the risk of clinically significant herb-drug interactions with echinacea is deemed low (Izzo, 2012).

\section{Elderberry (Sambucus nigra)}

The juice of the ripe berries of Sambucus nigra (SN) has long been used as a diaphoretic in the treatment of common colds (Teuscher, Willuhn, \& Loew, 2016). SN contains characteristic anthocyanins (mainly cyanidin3-O-glucoside, cyanidin-3-O-sambubuioside, cyanidin-3-O-sambubioside-5-O-glucoside and - depending on the cultivar -their coumaroyl-derivatives). Other constituents include flavonol-glycosides (e.g., rutin, kaempferol-, and isorhamnetin-3-O-rutinoside), caffeoylquinic acid derivatives, and organic acids such as citric, malic, and tartaric acid (Porter \& Bode, 2017; Teuscher et al., 2016).

Elderberry has immunomodulatory properties. In monocytes of healthy donors, a commercial formulation (Sambucol@, Razei Bar Industries, Ltd., Jerusalem, Israel) containing elderberry juice, stimulated production of the pro-inflammatory cytokines interleukin (IL)-1 $\beta$, IL-6, IL-8, and TNF- $\alpha$ (Barak, Halperin, \& Kalickman, 2001; Waknine-Grinberg, El-On, Barak, Barenholz, \& Golenser, 2009). Enhanced release of IL-6, IL-8 and TNF- $\alpha$ was also seen in the human alveolar carcinoma cell line A549 exposed to SN juice concentrate (Torabian, Valtchev, Adil, \& Dehghani, 2019). SN juice and methanolic extracts also produced a decrease in LPS-stimulated NF- $\kappa B$ activation, a key transcription factor involved in the immune response (Voldvik, 2015). A reduction of LPS-induced proinflammatory cytokines (IL-1 $\beta$, IL-6, TNF- $\alpha$ ) and COX-2 gene expression was reported in a murine macrophage model where the SN extract $(1 \mathrm{mg} / \mathrm{mL})$ had been exposed to a simulated gastrointestinal digestion process prior to the bioassay (Olejnik et al., 2015). Elderberry juice concentrate $(10 \mathrm{mg} /$ day) increases influenza A-specific neutralizing antibodies in bronchioalveolar lavage fluid of female BALB/c mice (Kinoshita, Hayashi, Katayama, Hayashi, \& Obata, 2012).

SN extracts have shown in vitro antiviral effects against influenza virus A and B. Three studies used proprietary products containing SN extracts (Sambucol® or Rubini ${ }^{\circledR}$, Iprona SpA, Lana, Italy) showed a reduction in infectious virus titre at dilutions ranging from 1:8 to 1:100 (Krawitz et al., 2011; Zakay-Rones et al., 1995). Sambucol-treated influenza A H9N2 virus-inoculated embryonic chicken eggs (95 mg/mL) resulted in a neutralizing index of $>7.7$, considered an effective antiviral treatment (Karimi, Mohammadi, \& Dadras, 2014). Antiviral effects of elderberry juice concentrate were reported in four publications; concentrations between 150-1000 $\mu \mathrm{g} / \mathrm{mL}$ showed impact on influenza A H1N1 (Kinoshita et al., 2012; Roschek Jr, Fink, McMichael, Li, \& Alberte, 2009), HIV (Fink, Roschek, \& Alberte, 2009), and IBV viruses (C. Chen et al., 2013).

Evidence from four human clinical trials demonstrate the effectiveness of SN in the treatment of upper respiratory infections by influenza or the common cold. A meta-analysis of these trials concluded that "supplementation with standardized elderberry extract is significantly effective at reducing the total duration and severity of upper respiratory symptoms, as compared to a placebo group" (Hawkins, Baker, Cherry, \& Dunne, 2019). 
A double-blind, placebo-controlled trial on healthy volunteers assessed elderberry consumption on proinflammatory cytokine levels. Subjects $(n=26)$ received elderberry extract (500 mg anthocyanins per day) whereas the control group $(n=26)$ received an equal amount of placebo capsules. After 12 weeks there was no statistical difference in measures of immunological parameters, e.g., IL-6, TNF- $\alpha$, RANTES, or C-reactive protein (CRP) (Curtis et al., 2009). Overall, the data on the immunomodulatory effects of elderberry extracts are inconsistent but based on the limited data on elderberry from this study, it appears the there is a low risk that elderberry intake would have a negative impact on the immune response during the course of COVID19.

Safety data from human studies and literature searches revealed no reports of significant adverse effects for short-term use of commercially available extracts (Ulbricht et al., 2014). Elderberry has no reported herbdrug interactions.

Despite the promising results reported in human clinical trials for the treatment of viral infections, any efficacy against the influenza virus cannot be used as an indication for a positive effect of elderberry in patients with COVID-19 as there are no scientific data supporting a positive outcome of elderberry in COVID19 patients. However, elderberry has an excellent safety profile, the available information suggesting a low risk of adverse effects when using elderberry prior to or at early stages of COVID-19.

\section{Umckaloabo (Pelargonium sidoides)}

Pelargonium sidoides (PS) is endemic to South Africa and Lesotho and the roots and rhizomes are important traditional medicine Preparations of PS, specifically EPs ${ }^{\circledR} 7630$ (Umckaloabo®, Schwabe Group, Karlsruhe, Germany), have undergone extensive clinical testing (Brendler \& Van Wyk, 2008).

Characteristic active constituents of PS are oxygenated coumarins, including 5,6,7-trimethoxycoumarin (umckalin), 6,8-dihydroxy-7-methoxycoumarin (fraxetin), 6,8-dihydoxy-5,7-dimethoxycoumarin (artelin), umckalin-7- $\beta$-glucoside, and 5,6-dimethoxycoumarin-7-sulfate (Brendler \& Van Wyk, 2008; Kolodziej, 2007; Schnitzler, Schneider, Stintzing, Carle, \& Reichling, 2008; Schötz \& Nöldner, 2007).

Immunostimulant activity of PS and its constituents has been assessed in several in-vitro models: infection with Leishmania, fibroblast-virus protection (for IFN activity) and fibroblast-lysis assays (for TNF- $\alpha$ activity), and biochemical and gene expression analyses. Interference with adhesion of microorganisms to cells, and stimulation of immune responses such as phagocytosis, oxidative burst, and intracellular killing of Candida albicans yeast by human peripheral blood phagocytes were demonstrated for PS in-vitro (Kolodziej, 2011; Kolodziej \& Kiderlen, 2007; Thale, Kiderlen, \& Kolodziej, 2011; K. Witte, Koch, Volk, Wolk, \& Sabat, 2015). EPs ${ }^{\circledR} 7630$ affected immune response in athletes during strenuous exercise by increasing of immunoglobulin $\alpha$ production in saliva, decreasing levels of interleukin (IL)-15 and IL- 6 in serum, and IL-15 in the nasal mucosa (Luna et al., 2011). EPs® 7630 increased IL-22 production, leading to increased antimicrobial proteins (AMPs) in airway epithelium, thus protecting against airway infection (Katrin Witte, Koch, Volk, Wolk, \& Sabat, 2020).

The antiviral activity of PS has shown for EPs® 7630, which inhibited virus replication for influenza virus H1N1 and H3N2, respiratory syncytial virus, human coronavirus (HCo-229E), parainfluenza virus type 3, and coxsackie virus A9, but not for non-enveloped adenovirus or rhinovirus (RV) (Michaelis, Doerr, \& Cinatl, 2011). EPs® 7630 increased human bronchial epithelial cell survival in RV infections by down-regulating cell membrane docking proteins and up-regulating host defence proteins $\beta$-defensin- 1 and SOCS- 1 (Roth, Fang, Stolz, \& Tamm, 2019). EPs® 7630 was found prevented asthma attacks provoked by RV in children, likely by decreasing inflammation caused by an increase in IL-6, IL-8, and IL-16 expression (Tahan \& Yaman, 2013).

More than 30 clinical trials have been conducted with EPs® 7630 over the last 25 years (total study population $>10,500$ ) in the treatment of acute respiratory tract infections. It is well tolerated, from $\sim 304$ million daily doses sold between 1994 and 2006 only 257 minor AEs were reported (Careddu \& Pettenazzo, 
2018; Matthys, Lehmacher, Zimmermann, Brandes, \& Kamin, 2016; Tahan \& Yaman, 2013; Timmer et al., 2013). Promising antiviral effects and an excellent safety profile warrant further clinical investigation (Kamin, Funk, Seifert, Zimmermann, \& Lehmacher, 2018; Andreas Schapowal et al., 2019).

\section{Medicinal Mushrooms and Fungal Preparations}

Medicinal fungi (commonly referred to as mushrooms, although fungi include underground mycelium whereas mushrooms are above-ground fruiting body) are of increasing research and clinical interest, with Pleurotus ostreatus (PO), Ganoderma spp. (GS), Inonotus obliquus (IO), Ophiocordyceps sinensis (OS), and Grifola frondosa (GF) being the most popular. Medicinal fungi are used in medicinal foods and dietary supplements, and in cosmeceuticals. Clinical studies on medicinal fungi preparations have been published in over 1,000 papers and reports. Approximately 300 clinical studies have been conducted on GS alone. Other mushrooms which have undergone clinical trials are Lentinula edodes, Trametes versicolor, Schizophyllum commune, Phellinus linteus, and Agaricus subrufescens. Most of this research focuses on treatment of cancers, immunological diseases, and immune-adjuvant therapy (S. P. Wasser, 2017).

Active compounds occur in fruiting bodies, cultured mycelium, and cultured broth. Medicinal fungi present a rich source of large molecular weight polysaccharides (especially $\beta$-glucans) and polysaccharide-protein complexes with anticancer and immunomodulating properties. Low-molecular-weight compounds (triterpenes, lectins, steroids, phenols, polyphenols, lactones, statins, and alkaloids) are also present and are similarly biologically active (Benson et al., 2019; Boh, 2013; Chang \& Wasser, 2012, 2018; Lindequist, 2013; Solomon P Wasser, 2010). Their effects on chronic blood-borne infections with influenza viruses A (subtype H5N1) and B (Teplyakova \& Kosogova, 2016) and SARS-CoV-2 (Murphy et al., 2020) are most relevant to COVID-19 issues.

Medicinal fungi have long been used to prevent immune disorders and maintain quality of life, especially in immunodeficient and immuno-depressed patients, and those being treated with chemotherapy or radiotherapy (Chang \& Wasser, 2012, 2018; Lindequist, 2013; Solomon P Wasser, 2010). Bioactive polysaccharides or polysaccharide-protein complexes from medicinal fungi appear to enhance innate and cell-mediated immune responses and exhibit antitumor activities in animals and humans. Clinical studies have clarified the basic mechanisms involved in the immunomodulatory activity of $\beta$-D-glucans, which bind to dectin-1 and complement receptor 3 (CR3) receptors (D. H. Lee \& Kim, 2014). CR3 and dectin-1 located on the surface of innate immune cells which can induce cytokine responses. Dectin-1 is expressed on macrophages, neutrophils, dendritic cells, and T lymphocytes. In clinical trials, medicinal fungi were shown to activate cytotoxic macrophages, monocytes, neutrophils, NK cells, dendritic cells, and cytokines, such as interleukins, interferons, and colony-stimulating factors, triggering complementary and acute phase responses. Medicinal fungi can be considered as multi-cytokine inducers, able to induce gene expression of immunomodulatory cytokines and cytokine receptors (Zmitrovich et al., 2019).

Results from clinical studies in cancer therapy cannot be transferred viral infections, but human studies have reported a stimulation of the innate immune system while not affecting, or slightly reducing, markers of inflammation. Multiple myeloma patients receiving a combination of extracts of $\mathrm{AB}$, GF, and Hericium erinaceus exhibited an increase in regulatory $\mathrm{T}$ cells and plasmacytoid dendritic cells, while concentrations of pro-inflammatory cytokines (IL-6, TNF- $\alpha$ ) did not change significantly when compared to placebo (Tangen et al., 2015). Healthy children receiving $\beta$-glucan (isolated from GL) in yoghurt showed significantly higher levels of circulating CD8+ T cells without a significant increase in cytokines IL-1 $\beta$, IL-6, IL-10, IL-12, and TNF$\alpha$ (Henao, Urrego, Cano, \& Higuita, 2018). A small study evaluating immune cell function in patients with myelodysplastic syndromes showed improved neutrophil and monocyte function in those patients receiving a GF extract compared to placebo group, although cytokine concentrations were not assessed (Wesa et al., 2015).

The effects of an $\alpha$-glucan obtained from basidiomycetes mushrooms were assessed in healthy volunteers receiving the influenza $B$ vaccine and showed higher concentrations of CD8+ T and NKT cells in those 
individuals receiving the mushroom preparation compared to the control group. No significant differences in cytokines IL-4, IL-6, IL-10 and IFN- $\gamma$ levels were reported, although the number of patients with measurable amounts of cytokines was low and results may not be reliable (Roman, Beli, Duriancik, \& Gardner, 2013).

The combination of immune cell activation combined with a moderate impact on inflammatory cytokines could be beneficial in patients with COVID-19. $\beta$-glucan-rich extracts from LE could be beneficial for COVID19 patients as cell-based studies show a reduction in pro-inflammatory cytokines (Murphy et al., 2020). The authors pointed out that there were substantial differences in the immunomodulatory effects depending on the extract composition, illustrating the difficulties inherent when assessing mushrooms as an entire category: there are distinct differences in the chemical compositions of the various species tested in in vitro, animal, and human studies. While glucans generally appear to be most closely linked to immunomodulatory effects, it is not clear how the glucan composition affects the clinical outcome.

Data with chemically well-defined fungal ingredients in COVID-19 patients are necessary to further evaluate if specific fungi indeed could be beneficial at certain stages of the disease. Clinical studies have reported mild gastrointestinal side effects (Klupp et al., 2015; Wesa et al., 2015), but generally the intake of fungal dietary supplements has a history of safe use in food and is not considered problematic.

\section{Adaptogens}

Adaptogens are natural compounds or mixtures thereof that increase adaptability, resilience, and survival of organisms (Alexander G. Panossian et al., 2020); they increase "the state of nonspecific resistance" of organisms (Lazarev, 1959) to harmful factors (Wagner, Norr, \& Winterhoff, 1994), including bacterial and viral pathogens. Nonspecific defence responses depend on the body's ability to recognize conserved features of pathogens by the innate immune system, which is activated at the onset of infection (Alberts et al., 2002). More than 100 medicinal plants have been attributed with adaptogenic activity; however, only few, Andrographis paniculata (AP), Eleutherococcus senticosus (ES), Panax spp. (ginseng, Psp), Rhodiola rosea (RR), Schisandra chinensis (SC), and Withania somnifera (ashwagandha, WS), have been shown to exhibit multitarget effects on the neuroendocrine-immune system, by triggering adaptive stress response, and increasing of non-specific resistance and adaptation in stress (A. Panossian, Seo, \& Efferth, 2018).

Specific antiviral, non-specific antiviral, anti-inflammatory, and detoxifying and cytoprotective effects have been demonstrated for active ingredients of these species: andrographolides in AP; eleutherosides in ES; ginsenosides in Psp; salidroside, rosavin, ellagic and gallic acids in RR; schisandrins and anwulignan in SC; and withanolides in WS, - in vitro and in vivo, and multiple molecular targets identified. Table 1 summarizes activities elucidated in pre-clinical investigations (Alexander Panossian \& Brendler, 2020).

Table 1. Direct and indirect effects (preclinical) of adaptogens on the immune response to a viral infection

\begin{tabular}{|c|c|c|c|c|c|c|}
\hline & AP & ES & Psp & $\mathbf{R R}$ & SC & WS \\
\hline \multicolumn{7}{|c|}{ Influenza, rhino-, and syncytial viruses } \\
\hline Human Rhinovirus (HRV) & & + & & & & \\
\hline Respiratory Syncytial Virus (RSV) & & + & + & & & \\
\hline H1N1 influenza A virus & ++ & ++ & ++ & + & & \\
\hline H3N2 influenza virus & & & ++ & & & \\
\hline H5N1 avian influenza virus & + & & ++ & + & & \\
\hline H7N9 influenza & & & + & & & \\
\hline H9N2 avian influenza virus & & & & + & & \\
\hline \multicolumn{7}{|c|}{ SARS structural and non-structural proteins involved in docking, RNA synthesis, and replication } \\
\hline $\mathrm{NSP}_{1}$ & + & & & & & \\
\hline $\mathrm{NSP}_{3}$ & + & ++ & ++ & ++ & ++ & \\
\hline $\mathrm{NSP}_{5}\left(\mathrm{M}_{\text {pro }}\right)$ & ++ & ++ & ++ & ++ & ++ & \\
\hline $\mathrm{NSP}_{12}$ & + & & & & & \\
\hline
\end{tabular}




\begin{tabular}{|c|c|c|c|c|c|c|}
\hline Spike protein S2 & + & & & & & \\
\hline \multicolumn{7}{|c|}{ Mediators of adaptive immune response } \\
\hline Defensins & ++ & & & & & \\
\hline TLRs & ++ & ++ & ++ & ++ & ++ & ++ \\
\hline Interferons & + & ++ & ++ & ++ & + & ++ \\
\hline Natural killer cells & & ++ & & + & + & + \\
\hline Interleukins & ++ & ++ & ++ & ++ & ++ & ++ \\
\hline Melatonin signalling pathways & & + & & + & + & + \\
\hline \multicolumn{7}{|c|}{ Components of adaptive immune response } \\
\hline T cells and MHC proteins & & ++ & & & + & ++ \\
\hline B cells and antibodies & + & + & & & & ++ \\
\hline \multicolumn{7}{|c|}{ Mediators of inflammatory response, antioxidant and detoxifying systems involved in cell- and tissue repair } \\
\hline PLA2s & + & & ++ & ++ & + & ++ \\
\hline COX-2 & ++ & + & ++ & ++ & & + \\
\hline Leukotrienes, lipoxins, resolvins & & + & & + & & ++ \\
\hline PAF & ++ & & ++ & & ++ & + \\
\hline NOC & ++ & + & ++ & + & ++ & + \\
\hline NFKB & ++ & ++ & ++ & ++ & ++ & ++ \\
\hline PI3K, PKB (Akt), KEAP1, Nrf2-ARE & ++ & + & ++ & ++ & ++ & ++ \\
\hline SOD, GST, NQ01, H01 & ++ & + & ++ & ++ & ++ & ++ \\
\hline Hsp72 & & ++ & & ++ & ++ & \\
\hline $\mathrm{ROR} \alpha$ & & + & & + & + & + \\
\hline
\end{tabular}

$(+)$ - evidence from one primary source, $(++)$ - evidence from multiple primary sources.

In a systematic review of 33 randomized clinical trials (RCTs) with AP (monotherapy and fixed combinations) in $>7,000$ patients, AP was shown to significantly improve overall symptoms of respiratory tract infections (RTIs) compared to placebo, usual care, and other herbal therapies. None of the studies reported major adverse events (AEs), minor AEs were mostly gastrointestinal (Hu et al., 2017).

More than 70 observational trials with ES, carried out in the 1970s and 80s in $>4,500$ subjects, reported an improvement of performance under stress, or stress related, cardiovascular, and pulmonary disorders. While all these studies would not meet modern standards, the sheer volume of favourable evidence cannot be ignored, and many results have been corroborated in more recent, well-conducted studies. Several studies investigating ES as a prophylactic agent found a reduction in overall disease incidence (up to 35\%), and a controlled and double-blinded study on influenza and RTIs in 1,376 subjects, found that which complications were found to be significantly lower with ES. Studies investigating the effect on morbidity caused by respiratory viral infections in $>900$ children receiving prophylactic ES treatment, found reduced morbidity rates of $30-40 \%$ (EMA, 2014).

Five RCTs with a fixed combination of AP and ES (KanJang®, KJ, Swedish Herbal Institute, Goteborg, Sweden) in $>1,000$ subjects confirmed relief of symptoms of uncomplicated RTIs caused by common cold (Caceres, Hancke, Burgos, \& Wikman, 1997; Gabrielian et al., 2002; Kulichenko, Kireyeva, Malyshkina, \& Wikman, 2003; Melchior, Spasov, Ostrovskij, Bulanov, \& Wikman, 2000; Spasov, Ostrovskij, Chernikov, \& Wikman, 2004). None of the studies reported any serious AEs, and a Periodic Safety Update Report for KJ (Anon., 2010), reported only 37 AEs (mainly allergic reactions) over 23 years out of 20 million daily doses sold.

Clinical evidence for efficacy and safety of Psp has been obtained primarily with two proprietary extracts, G115 (60+ trials) and COLD-fX (15+ trials) with $>12,000$ participants. Of relevance are 20 investigations with focus on immune response to RTI with a total study population $>3,400$ (Bilia \& Bergonzi, 2020; Iqbal \& Rhee, 2020), which produced significant evidence for immunomodulatory activity. A reduction in cytokine levels and oxidative stress decreased severity, duration, and symptom frequency, but also demonstrated potential for prevention of respiratory infections. All tested products were generally well tolerated, with only minor AEs reported. 
Systematic reviews of clinical trials and case reports involving RR with a combined study population $>3,500$ corroborate multiple pre-clinical findings of efficacy in areas of relief of stress and fatigue, viral infection, inflammation, and cardiovascular disease. All studies report a low incidence of minor AEs only (Anghelescu, Edwards, Seifritz, \& Kasper, 2018; EMA, 2012; A. Panossian, Wikman, \& Sarris, 2010; Pu et al., 2020; Tao et al., 2019; L. Yu et al., 2014).

Beneficial effects of SC as a mono-product and in combinations was postulated from clinical assessments conducted between 1950 and 1990 in a total study population >7,000 for a broad variety of indications $(2,800$ in infectious diseases like influenza, chronic sinusitis, otitis, neuritis, otosclerosis, and pneumonia). Although these studies showed methodological weaknesses (A. Panossian \& Wikman, 2008), many outcomes were corroborated in 29 more recent investigations (Aslanyan et al., 2010; Narimanian et al., 2005). Positive outcomes were observed in chemotherapy-induced immunosuppression (Kormosh, Laktionov, \& Antoshechkina, 2006), COPD (X. Yu, Zheng, Qian, Jiang, \& Wang, 2019), and fatigue (J. Park, Han, \& Park, 2020). SC was overall well tolerated with no or only mild AEs reported.

WS has recently been reviewed (Pratte, Nanavati, Young, \& Morley, 2014; Tandon \& Yadav, 2020), 33 clinical investigations with a total study population of $>2,500$ were identified. Outcomes included impact on stress, anxiety, cognitive improvement, and adaptogenic effects, which in most cases were deemed significant. No trial reported more than mild and transient AEs.

Next to immunity, the ability of adaptogens to alleviate stress-induced mental and behavioural disorders (A. G. Panossian, 2013) is relevant as these conditions have increased significantly since the onset of the COVID19 pandemic due to self-isolation (Stanton et al., 2020) and chronic exposure to stress and low-grade inflammation (Meftahi, Jangravi, Sahraei, \& Bahari, 2020).

\section{Liquorice (Glycyrrhiza spp.)}

Liquorice spp. (primarily Glycyrrhiza glabra, G. inflata, and G. uralensis) are native to the Europe and southwestern Asia, and widely cultivated. The root contains triterpenoid saponins (mostly glycyrrhizin), flavonoids, coumarins, and other phenolics (Asl \& Hosseinzadeh, 2008; Hosseinzadeh \& Nassiri-Asl, 2015). Glycyrrhizin is a potent anti-inflammatory agent, acting via suppression of NFKB translocation and decreasing the production of multiple pro-inflammatory mediators such as COX 2, iNOS, TNF- $\alpha$, IL-6, and levels of inflammatory modulators IL-10 and TGF- $\beta$ (R. Yang, Wang, Yuan, \& Liu, 2015).

The antiviral effects of glycyrrhizin and glycyrrhetinic acid have been reported in several studies (Fiore et al., 2008; H. Li et al., 2020; Wang et al., 2006). Glycyrrhizin inhibited replication of SARS-associated coronavirus (FFM-1 and FFM-2) isolated from patients in Vero cell cultures, possibly by inducing nitric oxide synthase. The highest activity of glycyrrhizin was observed during and after the adsorption time of the virus (Cinatl et al., 2003) and a derivative of glycyrrhizin, 2-acetamido- $\beta$-D-glucopyranosylamine was more effective against SARS-CoV Adding $\mathrm{N}$-acetylglucosamine residues to the glycyrrhizin molecule would increase hydrophilic properties, and perhaps binding to the carbohydrates of the S-proteins, thus inhibiting the entry of coronaviruses (Hoever et al., 2005).

The S-protein of SARS-CoV-2 binds to ACE2 with a higher affinity than SARS-CoV-1 (Wrapp et al., 2020). Docking studies show that glycyrrhizin may target the ACE2 receptor and prevent SARS-CoV-2 entry (H. Chen $\& \mathrm{Du}, 2020$ ). A further molecular docking study confirmed that glycyrrhizin has lower binding energy and could be active against SARS-CoV-2 (Li, Ma, Shen, \& Zhang, 2020), but research is needed investigate whether glycyrrhizin can prevent SARS-CoV-2 from entry to cells in vivo.

Glycyrrhizin inhibits PLA2 activity in in vitro (Matsumoto et al., 2013; Okimasu et al., 1983; Shiki et al., 1992; T. Y. Wu et al., 2011). Glycyrrhizin has anti-inflammatory effects in acute lung injury (ALI)-induced by lipopolysaccharide (LPS) in mice, inhibiting release of pro-inflammatory cytokines TNF- $\alpha$, IL-1 $\alpha$, and IL-6 and the infiltration of neutrophils via decreasing C-X-C chemokine receptor type 4/1 (CXCR4/CXCR1) expression, and expression of COX-2, iNOS, and NF- $\mathrm{KB}$ in bronchoalveolar lavage fluid, possibly via inhibition 
of the TLR-4/NF- $\mathrm{BB}$ signal pathway (S. A. Lee, Lee, Kim, \& Lee, 2019). The flavonoids of liquorice have antiinflammatory effects in an acute pulmonary inflammation model by LPS, reducing the infiltration of inflammatory cells (esp. neutrophils), oxidative stress, and pro-inflammatory mediator expression (TNF- $\alpha$, IL-1 $\beta$ ) in the lung (Xie, Dong, Wu, Yan, \& Xie, 2009). These effects are similar to those of drugs that mitigate the effects of cytokines released in response to the COVID-19 and limit lung damage in patients with severe disease (Rameshrad, Ghafoori, Mohammadpour, Nayeri, \& Hosseinzadeh, 2020).

$\beta$-Glycyrrhetinic acid, the major metabolite of glycyrrhizin, is a potent inhibitor of $11 \beta$-hydroxysteroid dehydrogenase (11 $\beta$-HSD) which causes an accumulation of glucocorticoids with anti-inflammatory properties (Asl \& Hosseinzadeh, 2008). $\beta$-Glycyrrhetinic acid also has an inhibitory effect on the 11 $\beta$-HSD enzyme in human lung tissue and enhances the activity of hydrocortisone, suggesting that coadministration of $\beta$-glycyrrhetinic acid with hydrocortisone may have a therapeutic effect in lung inflammatory diseases (Schleimer, 1991). In COVID-19 infection, neutrophils have a pivotal role in the development of lung oedema in ALI/ARDS and there are increasing pro-inflammatory cytokines in cytokine storms (Azkur et al., 2020), and glycyrrhizin may play a role in overcoming these two events. Glycyrrhizic acid was identified to be effective against SARS-CoV-2 target proteins in an in silico ADMET study (Vardhan \& Sahoo, 2020).

The most common herbal use of liquorice is in multi-ingredient TCM formulae. A meta-analysis of 18 clinical trials involving liquorice (at least $100 \mathrm{mg}$ of glycyrrhizic acid) showed a significant correlation between even moderate doses of liquorice and increases in systolic and diastolic blood pressure (Penninkilampi, Eslick, \& Eslick, 2017). Serum potassium, renin, and aldosterone are likewise significantly reduced, resulting in pseudo-hyperaldosteronism, which recently caused fatal cardiac arrythmia (Edelman, Butala, Avery, Lundquist, \& Dighe, 2020). Glycyrrhizic acid inhibits the activity of 11-beta-hydroxysteroid dehydrogenase, leading to an increase in the activity of endogenous glucocorticoids, and causes a subsequent loss of potassium, retention of sodium and water, and suppression of renin and aldosterone (Omar et al., 2012; R. Yang et al., 2015). Doses of $60 \mathrm{~g}$ of liquorice candy, or $100 \mathrm{mg}$ of glycyrrhizic acid, daily for two weeks can result in adverse events.

More studies are required to access new insights into the potential role of liquorice in the treatment of COVID-19. However, the potential benefits of liquorice are balanced against its adverse event profile (Nazari, Rameshrad, \& Hosseinzadeh, 2017).

\section{Turmeric (Curcuma longa)}

Curcuma longa, a rhizomatous herb growing in India, contains curcumin, which exerts a plethora of pharmacological actions of therapeutic interest. Standardized turmeric extracts with high levels of curcumin (up to 95\%) have been subjected to clinical research. Oral bioavailability of curcuminoids is generally poor, and methods used to improve bioavailability include the addition of piperine, binding to more soluble agents, or as nanoparticles (W. Liu et al., 2016).

An overview of systematic reviews provided evidence that curcumin-containing dietary supplements can exert systemic antioxidant actions which may alleviate inflammatory conditions and reduce cardiovascular risk factors (Pagano, Romano, Izzo, \& Borrelli, 2018).

Curcumin has demonstrated activity against a wide variety of viruses, by interfering with pathways controlling penetration and cellular signalling. It has been shown to interact with over 30 viral proteins including DNA polymerase and protein kinase and has been suggested as a potential agent for SARS-CoV-2 (Zahedipour et al., 2020). Curcumin may affect some of the pathophysiological and clinical features of COVID19, including virus penetration, cytokine storm-associated pulmonary fibrosis, and vascular coagulopathy (Zahedipour et al., 2020). Curcumin may potentially target critical steps of the viral replication cycle, including penetration and replication (Mathew \& Hsu, 2018). Curcumin inhibits ACE2 receptors and may thus prevent SARS-CoV-2 entry into the cell (Shanmugarajan, Prabitha, Kumar, \& Suresh, 2020). An in-silico investigation of potentially useful drugs found that curcumin, formed the most stable complex with SARS- 
CoV-2 main protease among those tested (Huynh, Wang, \& Luan, 2020). SARS-CoV-2 main protease activity is fundamental in viral maturation and it is a well-recognized drug target.

Responses are being evaluated in inflammation-induced alveolar damage and cytokine storms in COVID-19 patients (Schijns \& Lavelle, 2020). Curcumin blocks cytokine release, most importantly the pro-inflammatory interleukins IL- 1 , IL-6, and TNF- $\alpha$. This suppression by curcumin correlates with clinical improvement in animal models of diseases where a cytokine storm plays a prominent role in morbidity and mortality (Sordillo \& Helson, 2015). Curcumin has been shown to inhibit the release of IL-6 in rheumatoid synovial fibroblasts (Kloesch, Becker, Dietersdorfer, Kiener, \& Steiner, 2013), IL-8 in human oesophageal epithelial cells (Rafiee et al., 2009), and in alveolar epithelial cells (Biswas, McClure, Jimenez, Megson, \& Rahman, 2005). These properties are relevant to pulmonary diseases characterized by abnormal inflammatory responses, including pulmonary fibrosis (Lelli, Sahebkar, Johnston, \& Pedone, 2017). Curcumin modulated the inflammatory response inhibited fibrosis in a mouse model of viral-induced acute respiratory distress syndrome (Avasarala et al., 2013); the effect was associated with a reduction in the expression of key cytokines, including IL-6, in both the inflammatory infiltrate and whole lung tissue. Curcumin, in combination with an antibiotic therapy, protected mice against pulmonary inflammation and acute injury induced by Klebsiella pneumoniae (Bansal \& Chhibber, 2010).

Impaired coagulation is common in COVID-19, with disseminated intravascular coagulation present in most deceased patients (Boccia et al., 2020). Experimental evidence supports the positive actions of curcumin in haemostasis, anticoagulation, and fibrinolysis (Keihanian, Saeidinia, Bagheri, Johnston, \& Sahebkar, 2018). In a rodent model of disseminated intravascular coagulation induced by LPS, curcumin attenuated coagulopathy, renal injury, and mortality rate (H. W. Chen, Kuo, Chai, Ou, \& Yang, 2007). The effect was associated with a decrease of circulating TNF- $\alpha$ levels, the consumption of peripheral platelets and plasma fibrinogen (H. W. Chen et al., 2007).

Curcumin has been given in human trials up to a dose of $6 \mathrm{~g} / \mathrm{d}$ for 4-7 weeks without significant toxicity (Soleimani, Sahebkar, \& Hosseinzadeh, 2018). No serious adverse events were reported in meta-analysis of 22 clinical trials of curcumin for treatment of osteoarthritis, Alzheimer's, inflammatory bowel diseases, depression, and serum lipid reduction (Pagano et al., 2018).

In summary, curcumin has been shown to possess properties that may theoretically be of benefit in COVID19 pathophysiology and clinical manifestations.

\section{Frankincense (Boswellia spp.)}

The genus Boswellia comprises several species traditionally used for their medicinal properties, the most prominent being South Arabian and African B. sacra (syn. B. carteri), B. frereana, B. rivae, B. papyrifera, and Indian $B$. serrata. Research on frankincense exceeds 700 publications, mainly describing its role in treating anti-inflammatory chronic diseases such as osteoarthritis, inflammatory bowel disease, arthritis, and asthma (Abdel-Tawab, Werz, \& Schubert-Zsilavecz, 2011; A. Al-Harrasi, Csuk, Khan, \& Hussain, 2019; Ahmed AlHarrasi, Hussain, Csuk, \& Khan, 2018; H. Ammon, 2016).

The anti-inflammatory activity of frankincense extracts and its molecular targets and mechanism of action are well established. Boswellia extracts inhibit the synthesis of 6-keto-prostaglandin (PG) F1 $\alpha$, a product of cyclooxygenase 1 (COX-1) (H. P. Ammon, Mack, Singh, \& Safayhi, 1991) and suppress the synthesis of cytokine IL-1A-induced PGE2, COX-2, and synthesis of prostaglandin E synthase (Blain, Ali, \& Duance, 2010; Ranjbarnejad, Saidijam, Moradkhani, \& Najafi, 2017). Boswellic acids are COX-1 and prostaglandin E 2 synthase-1 inhibitors (Ulf Siemoneit et al., 2008; U Siemoneit et al., 2011) and both Boswellia extracts and boswellic acids inhibit leukotriene B4 (LTB4) and 5-hydroxyeicosatetraenoic acid (5-HETE) production via inhibition of 5-lipoxygenase (5-LOX) (Koeberle et al., 2018; Safayhi et al., 1992; Safayhi, Sailer, \& Ammon, 1995). Acetyl-11-keto- $\beta$-boswellic acid (AKBA) inhibits membrane-binding with catalytic domains of 5-LOX (Gilbert et al., 2020). A reduction in inflammatory mediators (IL-1ß, IL-6, TNF- $\alpha$, IFN- $\gamma$, and PGE2) and downregulation of IFN- $\gamma$ and IL-12 have been shown by Boswellia extracts and several boswellic acids, in 
particular AKBA (Gayathri, Manjula, Vinaykumar, Lakshmi, \& Balakrishnan, 2007; Morsy et al., 2019; Syrovets, Buchele, Krauss, Laumonnier, \& Simmet, 2005; Umar et al., 2014). Boswellia sacra and its triterpenoic compounds inhibited the proliferation, degranulation, and secretion of inflammatory mediators of anti-CD3 and anti-CD28 activated human T cells (Zimmermann-Klemd et al., 2020).

Most clinical data result from over 40 clinical trials with B. serrata preparations. Investigations have tested the effects of Boswellia and boswellic acids as mono-products and in combinations with other herbs in a study population $>2,000$ on various inflammation-related disease states (Cameron \& Chrubasik, 2014; Kafil et al., 2017; X. Liu, Machado, Eyles, Ravi, \& Hunter, 2018; Rajabian, Sadeghnia, Fanoudi, \& Hosseini, 2020). Most studies reported moderate efficacy, and no reports of serious AEs could be found.

There is insufficient evidence to advise against use of anti-inflammatory therapies in patients with COVID19. However, Boswellia extracts and their active components represent a promising approach for treatment of COVID-19-related inflammatory complications,

\section{Salicylate Drugs of Botanical Origin}

A range of herbs contain salicylic acid derivatives, including:

- Willow species Salix alba., S. daphnoides, S. x fragilis, S. purpurea and other spp.

- Meadowsweet, Filipendula ulmaria

- $\quad$ Birch (Betula spp., esp. Betula lenta)

- Wintergreen oil (Gaultheria procumbens)

These herbs contain NSAIDs and are inhibitors of COX-1 and / or COX-2. In April 2020, preliminary evidence assessment by the UK's National Institute for Clinical and Health Care Evidence (NICE) concluded that there is 'no evidence to determine if there is any increased risk of developing COVID-19 due to acute use of NSAIDs with people having an increased risk of contracting the disease' (https://www.nice.org.uk/advice/es23/resources/covid19-rapid-evidence-summary-acute-use-ofnonsteroidal-antiinflammatory-drugs-nsaids-for-people-with-or-at-risk-of-covid19-pdf-1158174128581).

NSAIDs remain a treatment option where indicated (https://www.ema.europa.eu/en/news/ema-givesadvice-use-non-steroidal-anti-inflammatories-covid-19), and while there is no specific guidance for herbal substances containing salicylic acid derivatives, the same applies provided that the preparations are generally considered safe.

Willow bark preparations are used in many European countries for fever, rheumatoid diseases, chronic pain, and headache. Salicin, the $\beta$-glucoside of salicylic alcohol, is metabolized to salicylic acid and was the lead molecule for the development of acetylsalicylic acid (aspirin). Widely used willow bark dry extracts contain a salicin content of 15-18\%. The special extract STW33-1 (Steigerwald, Germany) has shown strong inhibition of TNF- $\alpha$ and NFKB in activated monocytes (Bonaterra et al., 2010). A Cochrane review has concluded that there is low-to-moderate quality evidence that willow bark reduces acute and chronic lower back pain and has few adverse effects (Gagnier et al., 2016). It was superior to placebo for osteoarthritis and lower back pain with fewer adverse effects than aspirin (Oltean et al., 2014). While there are no safety assessments, the evidence points to willow preparations not posing a specific risk in the current COVID-19 pandemic.

Meadowsweet is indicated for the 'supportive treatment of common cold' and also 'for the relief of minor articular pain (EMA, 2011). Evidence is available for anti-inflammatory effects (Katanić et al., 2016), but overall, there are limited data supporting specific therapeutic benefits.

Preparations derived from birch are mostly used externally, for the alleviation of rheumatic pain and for eczema, but evidence for efficacy is weak. Topical preparations of wintergreen oil are used for sprains, rheumatism, sciatica, neuralgia, and muscular pain. With no immediate therapeutic benefits apparent, neither are relevant with reference to COVID-19 symptoms. 
Preparations containing salicylic acid derivatives are often used externally, and there is no evidence for any negative effects in the context of COVID-19. With internal use, there is no evidence that high-quality products pose a specific risk in patients with Covid-19

\section{Potential Drug Interactions of Herbal Medicines in Patients with COVID-19}

There is no evidence that immunomodulating herbs discussed here would cause excess immune stimulation, exacerbating a cytokine storm. Likewise, concerns raised over potential adverse effects of NSAI drugs on SARS-CoV-2 do not apply to herbs discussed above. Herb-drug interactions are not expected, especially with drugs used in mild-to-moderate disease or for symptom relief. When compared directly to drugs with similar actions, the AE profile of herbs is favourable. In fact, to date there are no case reports of relevant herbal interactions regarding COVID-19 treatment.

Remdesivir, initially developed to combat Ebola virus, has now been administered to $>1,800$ COVID-19 patients worldwide via clinical trials, compassionate use, and expanded access, and has shown mixed efficacy (Y. Yang, 2020). The U.S. Food and Drug Administration issued an Emergency Use Authorization for use of remdesivir for the treatment of hospitalized patients with COVID-19 on May 1, 2020. The potential for drug interactions involving remdesivir is a complex topic with varying conclusions from different studies. CYP inhibitors do not pose a significant risk of pharmacokinetic drug interaction, but strong CYP inducers may do so, reducing blood levels of remdesivir and resulting in treatment failure (Y. Yang, 2020). In the light of this possibility and because other antiviral agents have been shown to interact with Hypericum perforatum (St John's wort), concurrent use should be avoided. Other commonly used herbal medicines do not appear to pose a similar risk.

Hydroxychloroquine has famously been promoted as a COVID-19 treatment, and chloroquine to a lesser extent, but evidence for the benefits and harms of using either is conflicting (Hernandez, Roman, Pasupuleti, Barboza, \& White, 2020). Both have been used for many years for other indications and generally their drug interaction potential is low. A report from 2008 describes a patient suffering from acute hepatitis, prolonged cholestasis, and loss of interlobular bile ducts. taking hydroxychloroquine with tibolone and H. perforatum, concluding that the interaction was between tibolone and St John's wort, with hydroxychloroquine not playing a part (Etogo-Asse, Boemer, Sempoux, \& Geubel, 2008).

\section{Discussion / Conclusion}

The immunomodulatory botanicals discussed above demonstrated properties that improve parameters of the immune response, without evidence of risk of overstimulation, and may have the potential to decrease the risk of a cytokine storm. Adaptogens mitigate the adverse effects of physical and psychological stress and improve immune function and could provide real benefits. They are useful for the prevention and convalescence from viral infections. While no studies have yet been conducted on the impact of adaptogens on SARS-CoV-2 specifically, their effects on innate immunity, non-specific antiviral, anti-inflammatory, detoxifying and cytoprotective activities may apply here. Vaccines are becoming available but may not provide complete protection. Some botanicals have been shown to increase sero-conversion and thus vaccine efficacy.

Botanical drugs and supplements as sources of potential therapeutic agents for SARS-CoV-2 drug development are increasingly reported in the literature. Research is needed on mechanisms of action and effectiveness of phytotherapeutic interventions, in the context of SARS-CoV-2 exposure, with or without a vaccine, as adjunctive agents during onset or recovery.

Botanicals discussed here represent an option for use in the appropriate phase of COVID-19. Data are not strong enough to support active recommendation, but the balance of the evidence suggests that they are safe enough to permit use by members of the public, with appropriate caution. 


\section{Author Contributions}

Brendler - concept, team and project lead, pelargonium, adaptogens, editing; Al-Harrasi - frankincense; Bauer - echinacea; Gafner - elderberry, editing; Hardy - introduction and discussion, editing; Heinrich salicylate drugs; Hosseinzadeh, Nassiri-Asl - liquorice; Izzo - turmeric; Michaelis - SARS-CoV-2; Panossian adaptogens; Wasser - introduction, medicinal mushrooms; Williamson - herb drug interactions, safety, editing.

\section{Acknowledgements}

The authors express their gratitude to Mark Blumenthal, founder \& executive director of the American Botanical Council for his support.

\section{Competing Interests}

None declared.

\section{References}

Abdel-Tawab, M., Werz, O., \& Schubert-Zsilavecz, M. (2011). Boswellia serrata: an overall assessment of in vitro, preclinical, pharmacokinetic and clinical data. Clin Pharmacokinet, 50 (6), 349-369. doi:10.2165/11586800-000000000-00000

Al-Harrasi, A., Csuk, R., Khan, A., \& Hussain, J. (2019). Distribution of the anti-inflammatory and antidepressant compounds: Incensole and incensole acetate in genus Boswellia. Phytochemistry, 161, 28-40. doi:10.1016/j.phytochem.2019.01.007

Al-Harrasi, A., Hussain, H., Csuk, R., \& Khan, H. Y. (2018). Chemistry and bioactivity of boswellic acids and other terpenoids of the genus boswellia: Elsevier.

Al-Horani, R. A., Kar, S., \& Aliter, K. F. (2020). Potential Anti-COVID-19 Therapeutics that Block the Early Stage of the Viral Life Cycle: Structures, Mechanisms, and Clinical Trials. Int J Mol Sci, 21 (15). doi:10.3390/ijms21155224

Alberts, B., Johnson, A., Lewis, J., Raff, M., Roberts, K., \& Walter, P. (2002). Innate immunity. In Molecular Biology of the Cell. 4th edition: Garland Science.

Alschuler, L., Weil, A., Horwitz, R., Stamets, P., Chiasson, A. M., Crocker, R., \& Maizes, V. (2020). Integrative considerations during the COVID-19 pandemic. Explore (NY). doi:10.1016/j.explore.2020.03.007

Ammon, H. (2016). Boswellic acids and their role in chronic inflammatory diseases. In Anti-inflammatory Nutraceuticals and Chronic Diseases (pp. 291-327): Springer.

Ammon, H. P., Mack, T., Singh, G. B., \& Safayhi, H. (1991). Inhibition of leukotriene B4 formation in rat peritoneal neutrophils by an ethanolic extract of the gum resin exudate of Boswellia serrata. Planta Med, 57 (3), 203-207. doi:10.1055/s-2006-960074

Ang, L., Lee, H. W., Kim, A., \& Lee, M. S. (2020). Herbal medicine for the management of COVID-19 during the medical observation period: A review of guidelines. Integr Med Res, 9 (3), 100465. doi:10.1016/j.imr.2020.100465

Anghelescu, I.-G., Edwards, D., Seifritz, E., \& Kasper, S. (2018). Stress management and the role of Rhodiola rosea: a review. International Journal of Psychiatry in Clinical Practice, 22 (4), 242-252. doi:10.1080/13651501.2017.1417442

Anon. (2010). Periodic Safety Update Report for Kan Jang. Period covered by this Report: from 23 November 2006 to 22 November 2009. Retrieved from

Ardjomand-Woelkart, K., \& Bauer, R. (2016). Review and assessment of medicinal safety data of orally used Echinacea preparations. Planta medica, 82 (01/02), 17-31.

Asl, M. N., \& Hosseinzadeh, H. (2008). Review of pharmacological effects of Glycyrrhiza sp. and its bioactive compounds. Phytother Res, 22 (6), 709-724. doi:10.1002/ptr.2362 
Aslanyan, G., Amroyan, E., Gabrielyan, E., Nylander, M., Wikman, G., \& Panossian, A. (2010). Double-blind, placebo-controlled, randomised study of single dose effects of ADAPT-232 on cognitive functions. Phytomedicine, 17 (7), 494-499. doi:10.1016/j.phymed.2010.02.005

Avasarala, S., Zhang, F., Liu, G., Wang, R., London, S. D., \& London, L. (2013). Curcumin modulates the inflammatory response and inhibits subsequent fibrosis in a mouse model of viral-induced acute respiratory distress syndrome. PLOS ONE, 8 (2), e57285. doi:10.1371/journal.pone.0057285

Azkur, A. K., Akdis, M., Azkur, D., Sokolowska, M., van de Veen, W., Bruggen, M. C., ... Akdis, C. A. (2020). Immune response to SARS-CoV-2 and mechanisms of immunopathological changes in COVID-19. Allergy, 75 (7), 1564-1581. doi:10.1111/all.14364

Bansal, S., \& Chhibber, S. (2010). Curcumin alone and in combination with augmentin protects against pulmonary inflammation and acute lung injury generated during Klebsiella pneumoniae B5055induced lung infection in BALB/c mice. J Med Microbiol, 59 (Pt 4), 429-437. doi:10.1099/jmm.0.016873-0

Barak, V., Halperin, T., \& Kalickman, I. (2001). The effect of Sambucol, a black elderberry-based, natural product, on the production of human cytokines: I. Inflammatory cytokines. Eur Cytokine Netw, 12 (2), 290-296.

Beigel, J. H., Tomashek, K. M., Dodd, L. E., Mehta, A. K., Zingman, B. S., Kalil, A. C., . . Members, A.-S. G. (2020). Remdesivir for the Treatment of Covid-19 - Preliminary Report. $N$ Engl J Med. doi:10.1056/NEJMoa2007764

Benson, K. F., Stamets, P., Davis, R., Nally, R., Taylor, A., Slater, S., \& Jensen, G. S. (2019). The mycelium of the Trametes versicolor (Turkey tail) mushroom and its fermented substrate each show potent and complementary immune activating properties in vitro. BMC complementary and alternative medicine, 19 (1), 1-14.

Besedovsky, L., Lange, T., \& Haack, M. (2019). The Sleep-Immune Crosstalk in Health and Disease. Physiol Rev, 99 (3), 1325-1380. doi:10.1152/physrev.00010.2018

Bhala, N., Emberson, J., Merhi, A., Abramson, S., Arber, N., Baron, J. A., ... Baigent, C. (2013). Vascular and upper gastrointestinal effects of non-steroidal anti-inflammatory drugs: meta-analyses of individual participant data from randomised trials. Lancet, 382 (9894), 769-779. doi:10.1016/s0140-6736 (13)60900-9

Bilia, A. R., \& Bergonzi, M. C. (2020). The G115 standardized ginseng extract: an example for safety, efficacy, and quality of an herbal medicine. Journal of ginseng research, 44 (2), 179-193. doi:10.1016/j.jgr.2019.06.003

Biswas, S. K., McClure, D., Jimenez, L. A., Megson, I. L., \& Rahman, I. (2005). Curcumin induces glutathione biosynthesis and inhibits NF-kappaB activation and interleukin-8 release in alveolar epithelial cells: mechanism of free radical scavenging activity. Antioxid Redox Signal, 7 (1-2), 32-41. doi:10.1089/ars.2005.7.32

Blain, E. J., Ali, A. Y., \& Duance, V. C. (2010). Boswellia frereana (frankincense) suppresses cytokine-induced matrix metalloproteinase expression and production of pro-inflammatory molecules in articular cartilage. Phytother Res, 24 (6), 905-912. doi:10.1002/ptr.3055

Boccia, M., Aronne, L., Celia, B., Mazzeo, G., Ceparano, M., D'Agnano, V., ... Perrotta, F. (2020). COVID-19 and coagulative axis: review of emerging aspects in a novel disease. Monaldi Arch Chest Dis, 90 (2). doi:10.4081/monaldi.2020.1300

Boh, B. (2013). Ganoderma lucidum: a potential for biotechnological production of anti-cancer and immunomodulatory drugs. Recent Pat Anticancer Drug Discov, 8 (3), 255-287. doi:10.2174/1574891x113089990036

Bonaterra, G., Heinrich, E., Kelber, O., Weiser, D., Metz, J., \& Kinscherf, R. (2010). Anti-inflammatory effects of the willow bark extract STW 33-I (Proaktiv®) in LPS-activated human monocytes and differentiated macrophages. Phytomedicine, 17 (14), 1106-1113. 
Boozari, M., \& Hosseinzadeh, H. (2020). Natural products for COVID-19 prevention and treatment regarding to previous coronavirus infections and novel studies. Phytother Res. doi:10.1002/ptr.6873

Brendler, T., \& Van Wyk, B.-E. (2008). A historical, scientific and commercial perspective on the medicinal use of Pelargonium sidoides (Geraniaceae). Journal of ethnopharmacology, 119 (3), 420-433.

Caceres, D. D., Hancke, J. L., Burgos, R. A., \& Wikman, G. K. (1997). Prevention of common colds with Andrographis paniculata dried extract. A Pilot double blind trial. Phytomedicine, 4 (2), 101-104. doi:10.1016/S0944-7113 (97)80051-7

Cameron, M., \& Chrubasik, S. (2014). Oral herbal therapies for treating osteoarthritis. Cochrane Database Syst Rev, 5 (5), Cd002947. doi:10.1002/14651858.CD002947.pub2

Cao, X. (2020). COVID-19: immunopathology and its implications for therapy. Nat Rev Immunol, 20 (5), 269270. doi:10.1038/s41577-020-0308-3

Carayon, P., Marchand, J., Dussossoy, D., Derocq, J. M., Jbilo, O., Bord, A., . . Casellas, P. (1998). Modulation and functional involvement of CB2 peripheral cannabinoid receptors during B-cell differentiation. Blood, 92 (10), 3605-3615.

Careddu, D., \& Pettenazzo, A. (2018). Pelargonium sidoides extract EPs 7630: a review of its clinical efficacy and safety for treating acute respiratory tract infections in children. Int J Gen Med, 11, 91-98. doi:10.2147/IJGM.S154198

Carrillo, J. L. M., García, F. P. C., Coronado, O. G., García, M. A. M., \& Cordero, J. F. C. (2017). Physiology and pathology of innate immune response against pathogens. In Physiology and Pathology of Immunology: IntechOpen.

Cech, N. B., Kandhi, V., Davis, J. M., Hamilton, A., Eads, D., \& Laster, S. M. (2010). Echinacea and its alkylamides: Effects on the influenza A-induced secretion of cytokines, chemokines, and PGE2 from RAW 264.7 macrophage-like cells. International Immunopharmacology, 10 (10), 1268-1278.

Chang, S. T., \& Wasser, S. P. (2012). The role of culinary-medicinal mushrooms on human welfare with a pyramid model for human health. Int J Med Mushrooms, 14 (2), 95-134. doi:10.1615/intjmedmushr.v14.i2.10

Chang, S. T., \& Wasser, S. P. (2018). Current and Future Research Trends in Agricultural and Biomedical Applications of Medicinal Mushrooms and Mushroom Products (Review). Int J Med Mushrooms, 20 (12), 1121-1133. doi:10.1615/IntJMedMushrooms.2018029378

Channappanavar, R., \& Perlman, S. (2017). Pathogenic human coronavirus infections: causes and consequences of cytokine storm and immunopathology. Semin Immunopathol, 39 (5), 529-539. doi:10.1007/s00281-017-0629-x

Chen, C., Zuckerman, D., Brantley, S., Sharpe, M., Hoiczyk, E., \& Pendleton, A. (2013). Sambucus nigra Extracts Inhibit Infectious Bronchitis Virus at an Early Point during Replication. Planta medica, 79 (10), PN83.

Chen, H., \& Du, Q. (2020). Potential natural compounds for preventing SARS-CoV-2 (2019-nCoV) infection. Preprints.

Chen, H. W., Kuo, H. T., Chai, C. Y., Ou, J. L., \& Yang, R. C. (2007). Pretreatment of curcumin attenuates coagulopathy and renal injury in LPS-induced endotoxemia. J Endotoxin Res, 13 (1), 15-23. doi:10.1177/0968051907078605

Chen, Y., Liu, Q., \& Guo, D. (2020). Emerging coronaviruses: Genome structure, replication, and pathogenesis. J Med Virol, 92 (4), 418-423. doi:10.1002/jmv.25681

Cinatl, J., Morgenstern, B., Bauer, G., Chandra, P., Rabenau, H., \& Doerr, H. W. (2003). Glycyrrhizin, an active component of liquorice roots, and replication of SARS-associated coronavirus. Lancet, 361 (9374), 2045-2046. doi:10.1016/s0140-6736 (03)13615-x

Coll, R. C., \& O’Neill, L. A. J. (2010). New Insights into the Regulation of Signalling by Toll-Like Receptors and Nod-Like Receptors. Journal of Innate Immunity, 2 (5), 406-421. doi:10.1159/000315469 
Corman, V. M., Muth, D., Niemeyer, D., \& Drosten, C. (2018). Chapter Eight - Hosts and Sources of Endemic Human Coronaviruses. In M. Kielian, T. C. Mettenleiter, \& M. J. Roossinck (Eds.), Advances in Virus Research (Vol. 100, pp. 163-188): Academic Press.

Coronaviridae Study Group of the International Committee on Taxonomy of, V. (2020). The species Severe acute respiratory syndrome-related coronavirus: classifying 2019-nCoV and naming it SARS-CoV-2. Nature microbiology, 5 (4), 536-544. doi:10.1038/s41564-020-0695-z

Cui, J., Li, F., \& Shi, Z. L. (2019). Origin and evolution of pathogenic coronaviruses. Nat Rev Microbiol, 17 (3), 181-192. doi:10.1038/s41579-018-0118-9

Curtis, P. J., Kroon, P. A., Hollands, W. J., Walls, R., Jenkins, G., Kay, C. D., \& Cassidy, A. n. (2009). Cardiovascular disease risk biomarkers and liver and kidney function are not altered in postmenopausal women after ingesting an elderberry extract rich in anthocyanins for 12 weeks. The Journal of nutrition, 139 (12), 2266-2271.

David, S., \& Cunningham, R. (2019). Echinacea for the prevention and treatment of upper respiratory tract infections: A systematic review and meta-analysis. Complement Ther Med, 44, 18-26. doi:10.1016/j.ctim.2019.03.011

Domingo, P., Mur, I., Pomar, V., Corominas, H., Casademont, J., \& de Benito, N. (2020). The four horsemen of a viral Apocalypse: The pathogenesis of SARS-CoV-2 infection (COVID-19). EBioMedicine, 58, 102887. doi:10.1016/j.ebiom.2020.102887

Drozdzal, S., Rosik, J., Lechowicz, K., Machaj, F., Kotfis, K., Ghavami, S., \& Los, M. J. (2020). FDA approved drugs with pharmacotherapeutic potential for SARS-CoV-2 (COVID-19) therapy. Drug Resist Updat, 53, 100719. doi:10.1016/j.drup.2020.100719

Edelman, E. R., Butala, N. M., Avery, L. L., Lundquist, A. L., \& Dighe, A. S. (2020). Case 30-2020: A 54-Year-Old Man with Sudden Cardiac Arrest. New England Journal of Medicine, 383 (13), 1263-1275. doi:10.1056/NEJMcpc2002420

EMA. (2011). Assessment report on Filipendula ulmaria (L.) Maxim., herba and Filipendula ulmaria (L.) Maxim., flos. Committee on Herbal Medicinal Products (HMPC). EMA/HMPC/434892/2010.

EMA. (2012). Final assessment report on Rhodiola rosea. Committee on Herbal Medicinal Products (HMPC). EMA/HMPC/232100/2011.

EMA. (2014). Final assessment report on Eleutherococcus senticosus (Rupr. et Maxim.) Maxim., radix. Committee on Herbal Medicinal Products (HMPC). EMA/HMPC/680615/2013.

Etogo-Asse, F., Boemer, F., Sempoux, C., \& Geubel, A. (2008). Acute hepatitis with prolonged cholestasis and disappearance of interlobular bile ducts following tibolone and Hypericum perforatum (St. John's wort). Case of drug interaction? Acta Gastroenterol Belg, 71 (1), 36-38.

Fan, A. Y., Gu, S., \& Alemi, S. F. (2020). Chinese herbal medicine for COVID-19: Current evidence with systematic review and meta-analysis. J Integr Med, 18 (5), 385-394. doi:10.1016/j.joim.2020.07.008

Fasinu, P. S., \& Rapp, G. K. (2019). Herbal Interaction With Chemotherapeutic Drugs-A Focus on Clinically Significant Findings. Front Oncol, 9, 1356. doi:10.3389/fonc.2019.01356

Fierabracci, A., Arena, A., \& Rossi, P. (2020). COVID-19: A Review on Diagnosis, Treatment, and Prophylaxis. Int J Mol Sci, 21 (14). doi:10.3390/ijms21145145

Fink, R. C., Roschek, B., Jr., \& Alberte, R. S. (2009). HIV type-1 entry inhibitors with a new mode of action. Antivir Chem Chemother, 19 (6), 243-255. doi:10.1177/095632020901900604

Fiore, C., Eisenhut, M., Krausse, R., Ragazzi, E., Pellati, D., Armanini, D., \& Bielenberg, J. (2008). Antiviral effects of Glycyrrhiza species. Phytother Res, 22 (2), 141-148. doi:10.1002/ptr.2295

Fuzimoto, A. D., \& Isidoro, C. (2020). The antiviral and coronavirus-host protein pathways inhibiting properties of herbs and natural compounds - Additional weapons in the fight against the COVID-19 pandemic? J Tradit Complement Med, 10 (4), 405-419. doi:10.1016/j.jtcme.2020.05.003

Gabrielian, E. S., Shukarian, A. K., Goukasova, G. I., Chandanian, G. L., Panossian, A. G., Wikman, G., \& Wagner, H. (2002). A double blind, placebo-controlled study of Andrographis paniculata fixed combination Kan Jang in the treatment of acute upper respiratory tract infections including sinusitis. Phytomedicine, 9 (7), 589-597. doi:10.1078/094471102321616391 
Gagnier, J. J., Oltean, H., van Tulder, M. W., Berman, B. M., Bombardier, C., \& Robbins, C. B. (2016). Herbal Medicine for Low Back Pain: A Cochrane Review. Spine, 41 (2).

Gayathri, B., Manjula, N., Vinaykumar, K., Lakshmi, B., \& Balakrishnan, A. (2007). Pure compound from Boswellia serrata extract exhibits anti-inflammatory property in human PBMCs and mouse macrophages through inhibition of TNF $\alpha, \mathrm{IL}-1 \beta$, NO and MAP kinases. International Immunopharmacology, 7 (4), 473-482.

Gertsch, J., Schoop, R., Kuenzle, U., \& Suter, A. (2004). Echinacea alkylamides modulate TNF-alpha gene expression via cannabinoid receptor CB2 and multiple signal transduction pathways. FEBS Lett, 577 (3), 563-569. doi:10.1016/j.febslet.2004.10.064

Gilbert, N. C., Gerstmeier, J., Schexnaydre, E. E., Börner, F., Garscha, U., Neau, D. B., . . Newcomer, M. E. (2020). Structural and mechanistic insights into 5-lipoxygenase inhibition by natural products. Nature Chemical Biology, 1-8.

Gudbjartsson, D. F., Norddahl, G. L., Melsted, P., Gunnarsdottir, K., Holm, H., Eythorsson, E., ... Stefansson, K. (2020). Humoral Immune Response to SARS-CoV-2 in Iceland. N Engl J Med, 383 (18), 1724-1734. doi:10.1056/NEJMoa2026116

Gulledge, T. V., Collette, N. M., Mackey, E., Johnstone, S. E., Moazami, Y., Todd, D. A., .. Laster, S. M. (2018). Mast cell degranulation and calcium influx are inhibited by an Echinacea purpurea extract and the alkylamide dodeca-2E,4E-dienoic acid isobutylamide. J Ethnopharmacol, 212, 166-174. doi:10.1016/j.jep.2017.10.012

Hawkins, J., Baker, C., Cherry, L., \& Dunne, E. (2019). Black elderberry (Sambucus nigra) supplementation effectively treats upper respiratory symptoms: A meta-analysis of randomized, controlled clinical trials. Complement Ther Med, 42, 361-365. doi:10.1016/j.ctim.2018.12.004

Henao, S. L. D., Urrego, S. A., Cano, A. M., \& Higuita, E. A. (2018). Randomized Clinical Trial for the Evaluation of Immune Modulation by Yogurt Enriched with \&beta;-Glucans from Lingzhi or Reishi Medicinal Mushroom, $<\mathrm{i}>$ Ganoderma lucidum</i> (Agaricomycetes), in Children from Medellin, Colombia. 20 (8), 705-716. doi:10.1615/IntJMedMushrooms.2018026986

Hernandez, A. V., Roman, Y. M., Pasupuleti, V., Barboza, J. J., \& White, C. M. (2020). Hydroxychloroquine or chloroquine for treatment or prophylaxis of COVID-19: a living systematic review. Annals of Internal Medicine.

Hoever, G., Baltina, L., Michaelis, M., Kondratenko, R., Baltina, L., Tolstikov, G. A., .. Cinatl, J., Jr. (2005). Antiviral activity of glycyrrhizic acid derivatives against SARS-coronavirus. J Med Chem, 48 (4), 1256-1259. doi:10.1021/jm0493008

Hoffmann, M., Kleine-Weber, H., Schroeder, S., Kruger, N., Herrler, T., Erichsen, S., . . Pohlmann, S. (2020). SARS-CoV-2 Cell Entry Depends on ACE2 and TMPRSS2 and Is Blocked by a Clinically Proven Protease Inhibitor. Cell, 181 (2), 271-280 e278. doi:10.1016/j.cell.2020.02.052

Horby, P., Lim, W. S., Emberson, J., Mafham, M., Bell, J., Linsell, L., .. L Landray, M. J. (2020). Effect of Dexamethasone in Hospitalized Patients with COVID-19: Preliminary Report. medRxiv, 2020.2006.2022.20137273. doi:10.1101/2020.06.22.20137273

Hosseinzadeh, H., \& Nassiri-Asl, M. (2015). Pharmacological Effects of Glycyrrhiza spp. and Its Bioactive Constituents: Update and Review. Phytother Res, 29 (12), 1868-1886. doi:10.1002/ptr.5487

https://covid19.who.int/.

https://www.ema.europa.eu/en/news/ema-gives-advice-use-non-steroidal-anti-inflammatories-covid-19.

https://www.nice.org.uk/advice/es23/resources/covid19-rapid-evidence-summary-acute-use-ofnonsteroidal-antiinflammatory-drugs-nsaids-for-people-with-or-at-risk-of-covid19-pdf1158174128581.

https://www.who.int/emergencies/mers-cov/en/.

https://www.who.int/publications/m/item/summary-of-probable-sars-cases-with-onset-of-illness-from1-november-2002-to-31-july-2003.

Hu, X. Y., Wu, R. H., Logue, M., Blondel, C., Lai, L. Y. W., Stuart, B., . . Lewith, G. (2017). Andrographis paniculata (Chuan Xin Lian) for symptomatic relief of acute respiratory tract infections in adults 
and children: A systematic review and meta-analysis. PLOS ONE, 12 (8), e0181780. doi:10.1371/journal.pone.0181780

Hudson, J. B. (2012). Applications of the phytomedicine Echinacea purpurea (Purple Coneflower) in infectious diseases. J Biomed Biotechnol, 2012, 769896. doi:10.1155/2012/769896

Huynh, T., Wang, H., \& Luan, B. (2020). In Silico Exploration of the Molecular Mechanism of Clinically Oriented Drugs for Possibly Inhibiting SARS-CoV-2's Main Protease. J Phys Chem Lett, 11 (11), 44134420. doi:10.1021/acs.jpclett.0c00994

Iba, T., Levy, J. H., Levi, M., \& Thachil, J. (2020). Coagulopathy in COVID-19. J Thromb Haemost. doi:10.1111/jth.14975

Iqbal, H., \& Rhee, D. K. (2020). Ginseng alleviates microbial infections of the respiratory tract: a review. J Ginseng Res, 44 (2), 194-204. doi:10.1016/j.jgr.2019.12.001

Izzo, A. A. (2012). Interactions between herbs and conventional drugs: overview of the clinical data. Med Princ Pract, 21 (5), 404-428. doi:10.1159/000334488

Jawad, M., Schoop, R., Suter, A., Klein, P., \& Eccles, R. (2012). Safety and Efficacy Profile of Echinacea purpurea to Prevent Common Cold Episodes: A Randomized, Double-Blind, Placebo-Controlled Trial. Evid Based Complement Alternat Med, 2012, 841315. doi:10.1155/2012/841315

Kafil, T. S., Nguyen, T. M., Patton, P. H., MacDonald, J. K., Chande, N., \& McDonald, J. W. (2017). Interventions for treating collagenous colitis. Cochrane Database Syst Rev, 11 (11), Cd003575. doi:10.1002/14651858.CD003575.pub6

Kamin, W., Funk, P., Seifert, G., Zimmermann, A., \& Lehmacher, W. (2018). EPs 7630 is effective and safe in children under 6 years with acute respiratory tract infections: clinical studies revisited. Current medical research and opinion, 34 (3), 475-485.

Karimi, S., Mohammadi, A., \& Dadras, H. (2014). The effect of Echinacea purpurea and Sambucus nigra L. on H9N2 avian influenza virus in infected chicken embryo. Veterinarski arhiv, 84 (2), 153-165.

Katanić, J., Boroja, T., Mihailović, V., Nikles, S., Pan, S.-P., Rosić, G., ... Bauer, R. (2016). In vitro and in vivo assessment of meadowsweet (Filipendula ulmaria) as anti-inflammatory agent. Journal of ethnopharmacology, 193, 627-636.

Keihanian, F., Saeidinia, A., Bagheri, R. K., Johnston, T. P., \& Sahebkar, A. (2018). Curcumin, hemostasis, thrombosis, and coagulation. J Cell Physiol, 233 (6), 4497-4511. doi:10.1002/jcp.26249

Kinoshita, E., Hayashi, K., Katayama, H., Hayashi, T., \& Obata, A. (2012). Anti-influenza virus effects of elderberry juice and its fractions. Biosci Biotechnol Biochem, 76 (9), 1633-1638. doi:10.1271/bbb.120112

Kloesch, B., Becker, T., Dietersdorfer, E., Kiener, H., \& Steiner, G. (2013). Anti-inflammatory and apoptotic effects of the polyphenol curcumin on human fibroblast-like synoviocytes. Int Immunopharmacol, 15 (2), 400-405. doi:10.1016/j.intimp.2013.01.003

Klupp, N. L., Chang, D., Hawke, F., Kiat, H., Cao, H., Grant, S. J., \& Bensoussan, A. (2015). Ganoderma lucidum mushroom for the treatment of cardiovascular risk factors. Cochrane Database of Systematic Reviews (2).

Koeberle, A., Henkel, A., Verhoff, M., Tausch, L., König, S., Fischer, D., ... Jauch, J. (2018). Triterpene acids from frankincense and semi-synthetic derivatives that inhibit 5-lipoxygenase and cathepsin $\mathrm{g}$. Molecules, 23 (2), 506.

Kolodziej, H. (2007). Fascinating metabolic pools of Pelargonium sidoides and Pelargonium reniforme, traditional and phytomedicinal sources of the herbal medicine Umckaloabo®. Phytomedicine, 14, 917.

Kolodziej, H. (2011). Antimicrobial, antiviral and immunomodulatory activity studies of Pelargonium sidoides (EPs® 7630) in the context of health promotion. Pharmaceuticals, 4 (10), 1295-1314.

Kolodziej, H., \& Kiderlen, A. F. (2007). In vitro evaluation of antibacterial and immunomodulatory activities of Pelargonium reniforme, Pelargonium sidoides and the related herbal drug preparation EPs® 7630. Phytomedicine, 14, 18-26. 
Kormosh, N., Laktionov, K., \& Antoshechkina, M. (2006). Effect of a combination of extract from several plants on cell-mediated and humoral immunity of patients with advanced ovarian cancer. Phytother Res, 20 (5), 424-425. doi:10.1002/ptr.1889

Krawitz, C., Mraheil, M. A., Stein, M., Imirzalioglu, C., Domann, E., Pleschka, S., \& Hain, T. (2011). Inhibitory activity of a standardized elderberry liquid extract against clinically-relevant human respiratory bacterial pathogens and influenza A and B viruses. BMC Complement Altern Med, 11 (1), 16. doi:10.1186/1472-6882-11-16

Kulichenko, L. L., Kireyeva, L. V., Malyshkina, E. N., \& Wikman, G. (2003). A randomized, controlled study of Kan Jang versus amantadine in the treatment of influenza in Volgograd. J Herb Pharmacother, 3 (1), 77-93. doi:10.1080/J157v03n01_04

Lazarev, N. V. L., E.I.; Ljublina, M.A. (1959). State of nonspecific resistance. Patol. Fiziol. Experim. Terapia, 3, 16-21.

Lee, D. H., \& Kim, H. W. (2014). Innate immunity induced by fungal beta-glucans via dectin-1 signaling pathway. Int J Med Mushrooms, 16 (1), 1-16. doi:10.1615/intjmedmushr.v16.i1.10

Lee, S., Meyler, P., Mozel, M., Tauh, T., \& Merchant, R. (2020). Asymptomatic carriage and transmission of SARS-CoV-2: What do we know? Can J Anaesth, 67 (10), 1424-1430. doi:10.1007/s12630-02001729-X

Lee, S. A., Lee, S. H., Kim, J. Y., \& Lee, W. S. (2019). Effects of glycyrrhizin on lipopolysaccharide-induced acute lung injury in a mouse model. Journal of thoracic disease, 11 (4), 1287-1302. doi:10.21037/jtd.2019.04.14

Lelli, D., Sahebkar, A., Johnston, T. P., \& Pedone, C. (2017). Curcumin use in pulmonary diseases: State of the art and future perspectives. Pharmacological Research, 115, 133-148.

Letko, M., Marzi, A., \& Munster, V. (2020). Functional assessment of cell entry and receptor usage for SARSCoV-2 and other lineage B betacoronaviruses. Nature microbiology, 5 (4), 562-569. doi:10.1038/s41564-020-0688-y

Leyte-Lugo, M., Todd, D. A., Gulledge, T. V., Juzumaite, M., Carter, F. S., Laster, S. M., \& Cech, N. B. (2015). Cytokine-suppressive activity of a hydroxylated alkylamide from Echinacea purpurea. Planta Medica Letters, 2 (01), e25-e27.

Li, H., Hu, Y., Tang, H., Li, S., Ding, H., Zhai, S., \& Zhao, R. (2020). The Potential of Glycyrrhizinate in the Management of COVID-19: A Systematic Review of the Efficacy and Safety of Glycyrrhizin Preparations in the Treatment of SARS and MERS. The American Journal of Chinese Medicine, 48 (07), 1539-1552. doi:10.1142/s0192415x20500767

Li, J., Ma, X.-B., Shen, J., \& Zhang, Z.-F. (2020). Screening of active components from Chinese materia medica against SARS-CoV-2 based on literature mining and molecular docking. Chin. Trad. Herbal Drugs, 845-850.

Lindequist, U. (2013). The merit of medicinal mushrooms from a pharmaceutical point of view. Int J Med Mushrooms, 15 (6), 517-523. doi:10.1615/intjmedmushr.v15.i6.10

Little, P. (2020). Non-steroidal anti-inflammatory drugs and covid-19. BMJ, 368, m1185. doi:10.1136/bmj.m1185

Liu, W., Zhai, Y., Heng, X., Che, F. Y., Chen, W., Sun, D., \& Zhai, G. (2016). Oral bioavailability of curcumin: problems and advancements. J Drug Target, 24 (8), 694-702. doi:10.3109/1061186x.2016.1157883

Liu, X., Machado, G. C., Eyles, J. P., Ravi, V., \& Hunter, D. J. (2018). Dietary supplements for treating osteoarthritis: a systematic review and meta-analysis. British Journal of Sports Medicine, 52 (3), 167175. doi:10.1136/bjsports-2016-097333

Luna, L. A., Jr., Bachi, A. L., Novaes e Brito, R. R., Eid, R. G., Suguri, V. M., Oliveira, P. W., ... Vaisberg, M. (2011). Immune responses induced by Pelargonium sidoides extract in serum and nasal mucosa of athletes after exhaustive exercise: modulation of secretory IgA, IL-6 and IL-15. Phytomedicine, 18 (4), 303-308. doi:10.1016/j.phymed.2010.08.003

Mathew, D., \& Hsu, W.-L. (2018). Antiviral potential of curcumin. Journal of Functional Foods, 40, 692-699. 
Matsumoto, Y., Matsuura, T., Aoyagi, H., Matsuda, M., Hmwe, S. S., Date, T., . . Aizaki, H. (2013). Antiviral activity of glycyrrhizin against hepatitis C virus in vitro. PLOS ONE, 8 (7), e68992. doi:10.1371/journal.pone.0068992

Matthias, A., Banbury, L., Bone, K. M., Leach, D. N., \& Lehmann, R. P. (2008). Echinacea alkylamides modulate induced immune responses in T-cells. Fitoterapia, 79 (1), 53-58. doi:10.1016/j.fitote.2007.07.012

Matthys, H., Lehmacher, W., Zimmermann, A., Brandes, J., \& Kamin, W. (2016). EPs 7630 in acute respiratory tract infections-a systematic review and meta-analysis of randomized clinical trials. $J$ Lung Pulm Respir Res, 3 (1), 00068.

Meftahi, G. H., Jangravi, Z., Sahraei, H., \& Bahari, Z. (2020). The possible pathophysiology mechanism of cytokine storm in elderly adults with COVID-19 infection: the contribution of "inflame-aging". Inflamm Res, 69 (9), 825-839. doi:10.1007/s00011-020-01372-8

Meincke, R., Pokladnikova, J., Straznicka, J., Meyboom, R. H. B., Niedrig, D., Russmann, S., \& Jahodar, L. (2017). Allergy-like immediate reactions with herbal medicines in children: A retrospective study using data from VigiBase (®). Pediatr Allergy Immunol, 28 (7), 668-674. doi:10.1111/pai.12778

Melchior, J., Spasov, A. A., Ostrovskij, O. V., Bulanov, A. E., \& Wikman, G. (2000). Double-blind, placebocontrolled pilot and phase III study of activity of standardized Andrographis paniculata Herba Nees extract fixed combination (Kan jang) in the treatment of uncomplicated upper-respiratory tract infection. Phytomedicine, 7 (5), 341-350. doi:10.1016/S0944-7113 (00)80053-7

Michaelis, M., Doerr, H. W., \& Cinatl, J., Jr. (2011). Investigation of the influence of EPs (R) 7630, a herbal drug preparation from Pelargonium sidoides, on replication of a broad panel of respiratory viruses. Phytomedicine, 18 (5), 384-386. doi:10.1016/j.phymed.2010.09.008

Morris, G., Bortolasci, C. C., Puri, B. K., Olive, L., Marx, W., O'Neil, A., ... Berk, M. (2020). The pathophysiology of SARS-CoV-2: A suggested model and therapeutic approach. Life Sci, 258, 118166. doi:10.1016/j.lfs.2020.118166

Morsy, M. A., Patel, S. S., El-Sheikh, A. A. K., Savjani, J. K., Nair, A. B., Shah, J. N., \& Venugopala, K. N. (2019). Computational and Biological Comparisons of Plant Steroids as Modulators of Inflammation through Interacting with Glucocorticoid Receptor. Mediators Inflamm, 2019, 3041438. doi:10.1155/2019/3041438

Murphy, E. J., Masterson, C., Rezoagli, E., O'Toole, D., Major, I., Stack, G. D., . . Rowan, N. J. (2020). $\beta$-Glucan extracts from the same edible shiitake mushroom Lentinus edodes produce differential in-vitro immunomodulatory and pulmonary cytoprotective effects-Implications for coronavirus disease (COVID-19) immunotherapies. Science of the Total Environment, 139330.

Narimanian, M., Badalyan, M., Panosyan, V., Gabrielyan, E., Panossian, A., Wikman, G., \& Wagner, H. (2005). Impact of Chisan (ADAPT-232) on the quality-of-life and its efficacy as an adjuvant in the treatment of acute non-specific pneumonia. Phytomedicine, 12 (10), 723-729. doi:10.1016/j.phymed.2004.11.004

Nazari, S., Rameshrad, M., \& Hosseinzadeh, H. (2017). Toxicological Effects of Glycyrrhiza glabra (Licorice): A Review. Phytother Res, 31 (11), 1635-1650. doi:10.1002/ptr.5893

Ni, W., Yang, X., Yang, D., Bao, J., Li, R., Xiao, Y., ... Gao, Z. (2020). Role of angiotensin-converting enzyme 2 (ACE2) in COVID-19. Crit Care, 24 (1), 422. doi:10.1186/s13054-020-03120-0

Nowill, A. E., \& de Campos-Lima, P. O. (2020). Immune Response Resetting as a Novel Strategy to Overcome SARS-CoV-2-Induced Cytokine Storm. J Immunol. doi:10.4049/jimmunol.2000892

Okimasu, E., Moromizato, Y., Watanabe, S., Sasaki, J., Shiraishi, N., Morimoto, Y. M., ... Utsumi, K. (1983). Inhibition of phospholipase A2 and platelet aggregation by glycyrrhizin, an antiinflammation drug. Acta Med Okayama, 37 (5), 385-391. doi:10.18926/AM0/32426

Olejnik, A., Kowalska, K., Olkowicz, M., Rychlik, J., Juzwa, W., Myszka, K., ... Białas, W. (2015). Antiinflammatory effects of gastrointestinal digested Sambucus nigra L. fruit extract analysed in cocultured intestinal epithelial cells and lipopolysaccharide-stimulated macrophages. Journal of Functional Foods, 19, 649-660. 
Oltean, H., Robbins, C., van Tulder, M. W., Berman, B. M., Bombardier, C., \& Gagnier, J. J. (2014). Herbal medicine for low-back pain. Cochrane Database Syst Rev (12), CD004504. doi:10.1002/14651858.CD004504.pub4

Omar, H. R., Komarova, I., El-Ghonemi, M., Fathy, A., Rashad, R., Abdelmalak, H. D., . . Camporesi, E. M. (2012). Licorice abuse: time to send a warning message. Ther Adv Endocrinol Metab, 3 (4), 125-138. doi:10.1177/2042018812454322

Pagano, E., Romano, B., Izzo, A. A., \& Borrelli, F. (2018). The clinical efficacy of curcumin-containing nutraceuticals: An overview of systematic reviews. Pharmacol Res, 134, 79-91. doi:10.1016/j.phrs.2018.06.007

Panossian, A., \& Brendler, T. (2020). The Role of Adaptogens in Prophylaxis and Treatment of Viral Respiratory Infections. Pharmaceuticals, 13 (9), 236.

Panossian, A., Seo, E. J., \& Efferth, T. (2018). Novel molecular mechanisms for the adaptogenic effects of herbal extracts on isolated brain cells using systems biology. Phytomedicine, 50, 257-284. doi:10.1016/j.phymed.2018.09.204

Panossian, A., \& Wikman, G. (2008). Pharmacology of Schisandra chinensis Bail.: an overview of Russian research and uses in medicine. J Ethnopharmacol, 118 (2), 183-212. doi:10.1016/j.jep.2008.04.020

Panossian, A., Wikman, G., \& Sarris, J. (2010). Rosenroot (Rhodiola rosea): Traditional use, chemical composition, pharmacology and clinical efficacy. Phytomedicine, 17 (7), 481-493. doi:10.1016/j.phymed.2010.02.002

Panossian, A. G. (2013). Adaptogens in mental and behavioral disorders. Psychiatr Clin North Am, 36 (1), 4964. doi:10.1016/j.psc.2012.12.005

Panossian, A. G., Efferth, T., Shikov, A. N., Pozharitskaya, O. N., Kuchta, K., Mukherjee, P. K., ... Wagner, H. (2020). Evolution of the adaptogenic concept from traditional use to medical systems: Pharmacology of stress- and aging-related diseases. Medicinal Research Reviews, $n / a$ (n/a). doi:10.1002/med.21743

Park, J., Han, S., \& Park, H. (2020). Effect of Schisandra chinensis Extract Supplementation on Quadriceps Muscle Strength and Fatigue in Adult Women: A Randomized, Double-Blind, Placebo-Controlled Trial. International Journal of Environmental Research and Public Health, 17 (7), 2475.

Park, S., Lee, M. S., Jung, S., Lee, S., Kwon, O., Kreuter, M. H., . . Kim, Y. (2018). Echinacea purpurea Protects Against Restraint Stress-Induced Immunosuppression in BALB/c Mice. J Med Food, 21 (3), 261-268. doi:10.1089/jmf.2017.4073

Penninkilampi, R., Eslick, E. M., \& Eslick, G. D. (2017). The association between consistent licorice ingestion, hypertension and hypokalaemia: a systematic review and meta-analysis. J Hum Hypertens, 31 (11), 699-707. doi:10.1038/jhh.2017.45

Perez-Saez, J., Lauer, S. A., Kaiser, L., Regard, S., Delaporte, E., Guessous, I., . . Azman, A. S. (2020). Serologyinformed estimates of SARS-CoV-2 infection fatality risk in Geneva, Switzerland. Lancet Infect Dis. doi:10.1016/s1473-3099 (20)30584-3

Petersen, E., Koopmans, M., Go, U., Hamer, D. H., Petrosillo, N., Castelli, F., ... Simonsen, L. (2020). Comparing SARS-CoV-2 with SARS-CoV and influenza pandemics. Lancet Infect Dis, 20 (9), e238e244. doi:10.1016/s1473-3099 (20)30484-9

Pleschka, S., Stein, M., Schoop, R., \& Hudson, J. B. (2009). Anti-viral properties and mode of action of standardized Echinacea purpurea extract against highly pathogenic avian influenza virus (H5N1, H7N7) and swine-origin H1N1 (S-OIV). Virol J, 6, 197. doi:10.1186/1743-422X-6-197

Poletti, P., Tirani, M., Cereda, D., Trentini, F., Guzzetta, G., Marziano, V., . . . Merler, S. (2020). Age-specific SARS-CoV-2 infection fatality ratio and associated risk factors, Italy, February to April 2020. Euro Surveill, 25 (31). doi:10.2807/1560-7917.Es.2020.25.31.2001383

Pollán, M., Pérez-Gómez, B., Pastor-Barriuso, R., Oteo, J., Hernán, M. A., Pérez-Olmeda, M., ... Yotti, R. (2020). Prevalence of SARS-CoV-2 in Spain (ENE-COVID): a nationwide, population-based seroepidemiological study. Lancet, 396 (10250), 535-544. doi:10.1016/s0140-6736 (20)31483-5 
Porter, R. S., \& Bode, R. F. (2017). A Review of the Antiviral Properties of Black Elder (Sambucus nigra L.) Products. Phytotherapy Research, 31 (4), 533-554. doi:10.1002/ptr.5782

Pratte, M. A., Nanavati, K. B., Young, V., \& Morley, C. P. (2014). An alternative treatment for anxiety: a systematic review of human trial results reported for the Ayurvedic herb ashwagandha (Withania somnifera). J Altern Complement Med, 20 (12), 901-908. doi:10.1089/acm.2014.0177

Pu, W.-l., Zhang, M.-y., Bai, R.-y., Sun, L.-k., Li, W.-h., Yu, Y.-l., . . Li, T.-x. (2020). Anti-inflammatory effects of Rhodiola rosea L.: A review. Biomedicine \& Pharmacotherapy, 121, 109552. doi:10.1016/j.biopha.2019.109552

Raduner, S., Majewska, A., Chen, J. Z., Xie, X. Q., Hamon, J., Faller, B., .. Gertsch, J. (2006). Alkylamides from Echinacea are a new class of cannabinomimetics. Cannabinoid type 2 receptor-dependent and independent immunomodulatory effects. J Biol Chem, 281 (20), 14192-14206. doi:10.1074/jbc.M601074200

Rafiee, P., Nelson, V. M., Manley, S., Wellner, M., Floer, M., Binion, D. G., \& Shaker, R. (2009). Effect of curcumin on acidic pH-induced expression of IL-6 and IL-8 in human esophageal epithelial cells (HET-1A): role of PKC, MAPKs, and NF-kappaB. Am J Physiol Gastrointest Liver Physiol, 296 (2), G388-398. doi:10.1152/ajpgi.90428.2008

Rajabian, A., Sadeghnia, H., Fanoudi, S., \& Hosseini, A. (2020). Genus Boswellia as a new candidate for neurodegenerative disorders. Iranian journal of basic medical sciences, 23 (3), 277-286. doi:10.22038/IJBMS.2020.35288.8419

Rameshrad, M., Ghafoori, M., Mohammadpour, A. H., Nayeri, M. J. D., \& Hosseinzadeh, H. (2020). A comprehensive review on drug repositioning against coronavirus disease 2019 (COVID19). Naunyn Schmiedebergs Arch Pharmacol, 393 (7), 1137-1152. doi:10.1007/s00210-020-01901-6

Ranjbarnejad, T., Saidijam, M., Moradkhani, S., \& Najafi, R. (2017). Methanolic extract of Boswellia serrata exhibits anti-cancer activities by targeting microsomal prostaglandin E synthase- 1 in human colon cancer cells. Prostaglandins Other Lipid Mediat, 131, 1-8. doi:10.1016/j.prostaglandins.2017.05.003

Rockwell, C. E., Raman, P., Kaplan, B. L., \& Kaminski, N. E. (2008). A COX-2 metabolite of the endogenous cannabinoid, 2-arachidonyl glycerol, mediates suppression of IL-2 secretion in activated Jurkat T cells. Biochem Pharmacol, 76 (3), 353-361. doi:10.1016/j.bcp.2008.05.005

Roman, B. E., Beli, E., Duriancik, D. M., \& Gardner, E. M. (2013). Short-term supplementation with active hexose correlated compound improves the antibody response to influenza B vaccine. Nutrition Research, 33 (1), 12-17. doi:10.1016/j.nutres.2012.11.001

Roschek Jr, B., Fink, R. C., McMichael, M. D., Li, D., \& Alberte, R. S. (2009). Elderberry flavonoids bind to and prevent H1N1 infection in vitro. Phytochemistry, 70 (10), 1255-1261.

Rossi, F., Tortora, C., Argenziano, M., Di Paola, A., \& Punzo, F. (2020). Cannabinoid Receptor Type 2: A Possible Target in SARS-CoV-2 (CoV-19) Infection? Int J Mol Sci, 21 (11), 3809. doi:10.3390/ijms21113809

Roth, M., Fang, L., Stolz, D., \& Tamm, M. (2019). Pelargonium sidoides radix extract EPs 7630 reduces rhinovirus infection through modulation of viral binding proteins on human bronchial epithelial cells. PLOS ONE, 14 (2), e0210702. doi:10.1371/journal.pone.0210702

Ruan, Q., Yang, K., Wang, W., Jiang, L., \& Song, J. (2020). Clinical predictors of mortality due to COVID-19 based on an analysis of data of 150 patients from Wuhan, China. Intensive Care Med, 46 (5), 846848. doi:10.1007/s00134-020-05991-x

Safayhi, H., Mack, T., Sabieraj, J., Anazodo, M. I., Subramanian, L. R., \& Ammon, H. P. (1992). Boswellic acids: novel, specific, nonredox inhibitors of 5-lipoxygenase. J Pharmacol Exp Ther, 261 (3), 1143-1146.

Safayhi, H., Sailer, E. R., \& Ammon, H. P. (1995). Mechanism of 5-lipoxygenase inhibition by acetyl-11-ketobeta-boswellic acid. Mol Pharmacol, 47 (6), 1212-1216.

Schapowal, A., Dobos, G., Cramer, H., Ong, K. C., Adler, M., Zimmermann, A., .. Lehmacher, W. (2019). Treatment of signs and symptoms of the common cold using EPs 7630 - results of a meta-analysis. Heliyon, 5 (11), e02904. doi:10.1016/j.heliyon.2019.e02904 
Schapowal, A., Klein, P., \& Johnston, S. L. (2015). Echinacea reduces the risk of recurrent respiratory tract infections and complications: a meta-analysis of randomized controlled trials. Adv Ther, 32 (3), 187200. doi:10.1007/s12325-015-0194-4

Schijns, V., \& Lavelle, E. C. (2020). Prevention and treatment of COVID-19 disease by controlled modulation of innate immunity. Eur J Immunol, 50 (7), 932-938. doi:10.1002/eji.202048693

Schleimer, R. P. (1991). Potential regulation of inflammation in the lung by local metabolism of hydrocortisone. Am J Respir Cell Mol Biol, 4 (2), 166-173. doi:10.1165/ajrcmb/4.2.166

Schnitzler, P., Schneider, S., Stintzing, F. C., Carle, R., \& Reichling, J. (2008). Efficacy of an aqueous Pelargonium sidoides extract against herpesvirus. Phytomedicine, 15 (12), 1108-1116. doi:10.1016/j.phymed.2008.06.009

Schötz, K., \& Nöldner, M. (2007). Mass spectroscopic characterisation of oligomeric proanthocyanidins derived from an extract of Pelargonium sidoides roots (EPs® 7630) and pharmacological screening in CNS models. Phytomedicine, 14, 32-39.

Sethi, A., \& Bach, H. (2020). Evaluation of Current Therapies for COVID-19 Treatment. Microorganisms, 8 (8). doi:10.3390/microorganisms8081097

Shang, J., Wan, Y., Luo, C., Ye, G., Geng, Q., Auerbach, A., \& Li, F. (2020). Cell entry mechanisms of SARS-CoV2. Proc Natl Acad Sci U S A, 117 (21), 11727-11734. doi:10.1073/pnas.2003138117

Shanmugarajan, D., Prabitha, P., Kumar, B. P., \& Suresh, B. (2020). Curcumin to inhibit binding of spike glycoprotein to ACE2 receptors: computational modelling, simulations, and ADMET studies to explore curcuminoids against novel SARS-CoV-2 targets. RSC Advances, 10 (52), 31385-31399.

Sharma, M., Anderson, S. A., Schoop, R., \& Hudson, J. B. (2009). Induction of multiple pro-inflammatory cytokines by respiratory viruses and reversal by standardized Echinacea, a potent antiviral herbal extract. Antiviral Res, 83 (2), 165-170. doi:10.1016/j.antiviral.2009.04.009

Sharma, M., Arnason, J. T., \& Hudson, J. B. (2006). Echinacea extracts modulate the production of multiple transcription factors in uninfected cells and rhinovirus-infected cells. Phytother Res, 20 (12), 10741079. doi:10.1002/ptr.1998

Shiki, Y., Shirai, K., Saito, Y., Yoshida, S., Mori, Y., \& Wakashin, M. (1992). Effect of glycyrrhizin on lysis of hepatocyte membranes induced by anti-liver cell membrane antibody. J Gastroenterol Hepatol, 7 (1), 12-16. doi:10.1111/j.1440-1746.1992.tb00927.x

Siemoneit, U., Hofmann, B., Kather, N., Lamkemeyer, T., Madlung, J., Franke, L., ... Werz, O. (2008). Identification and functional analysis of cyclooxygenase- 1 as a molecular target of boswellic acids. Biochemical Pharmacology, 75 (2), 503-513.

Siemoneit, U., Koeberle, A., Rossi, A., Dehm, F., Verhoff, M., Reckel, S., ... Bernhard, F. (2011). Inhibition of microsomal prostaglandin E2 synthase-1 as a molecular basis for the anti-inflammatory actions of boswellic acids from frankincense. British Journal of Pharmacology, 162 (1), 147-162.

Signer, J., Jonsdottir, H. R., Albrich, W. C., Strasser, M., Züst, R., Ryter, S., . . Engler, O. B. (2020). In vitro virucidal activity of Echinaforce $\AA$, an Echinacea purpurea preparation, against coronaviruses, including common cold coronavirus 229E and SARS-CoV-2. Virol J, 17 (1), 136. doi:10.1186/s12985-020-01401-2

Silveira, D., Prieto-Garcia, J. M., Boylan, F., Estrada, O., Fonseca-Bazzo, Y. M., Jamal, C. M., ... Heinrich, M. (2020). COVID-19: Is there evidence for the use of herbal medicines as adjuvant symptomatic therapy? Frontiers in Pharmacology, 11, 1479.

Soleimani, V., Sahebkar, A., \& Hosseinzadeh, H. (2018). Turmeric (Curcuma longa) and its major constituent (curcumin) as nontoxic and safe substances. Phytotherapy Research, 32 (6), 985-995.

Sordillo, P. P., \& Helson, L. (2015). Curcumin suppression of cytokine release and cytokine storm. A potential therapy for patients with Ebola and other severe viral infections. in vivo, 29 (1), 1-4.

Spasov, A. A., Ostrovskij, O. V., Chernikov, M. V., \& Wikman, G. (2004). Comparative controlled study of Andrographis paniculata fixed combination, Kan Jang® and an Echinacea preparation as adjuvant, in the treatment of uncomplicated respiratory disease in children. Phytotherapy Research, 18 (1), 47-53. doi:10.1002/ptr.1359 
Stanton, R., To, Q. G., Khalesi, S., Williams, S. L., Alley, S. J., Thwaite, T. L., ... Vandelanotte, C. (2020). Depression, Anxiety and Stress during COVID-19: Associations with Changes in Physical Activity, Sleep, Tobacco and Alcohol Use in Australian Adults. International Journal of Environmental Research and Public Health, 17 (11), 4065.

Syrovets, T., Buchele, B., Krauss, C., Laumonnier, Y., \& Simmet, T. (2005). Acetyl-boswellic acids inhibit lipopolysaccharide-mediated TNF-alpha induction in monocytes by direct interaction with IkappaB kinases. J Immunol, 174 (1), 498-506. doi:10.4049/jimmunol.174.1.498

Tahan, F., \& Yaman, M. (2013). Can the Pelargonium sidoides root extract EPs (R) 7630 prevent asthma attacks during viral infections of the upper respiratory tract in children? Phytomedicine, 20 (2), 148150. doi:10.1016/j.phymed.2012.09.022

Tandon, N., \& Yadav, S. S. (2020). Safety and clinical effectiveness of Withania Somnifera (Linn.) Dunal root in human ailments. J Ethnopharmacol, 255, 112768. doi:10.1016/j.jep.2020.112768

Tangen, J.-M., Tierens, A., Caers, J., Binsfeld, M., Olstad, O. K., Trøseid, A.-M. S., ... Hetland, G. (2015). Immunomodulatory Effects of the $<i>$ Agaricus blazei $</ i>$ Murrill-Based Mushroom Extract AndoSan in Patients with Multiple Myeloma Undergoing High Dose Chemotherapy and Autologous Stem Cell Transplantation: A Randomized, Double Blinded Clinical Study. BioMed Research International, 2015, 718539. doi:10.1155/2015/718539

Tao, H., Wu, X., Cao, J., Peng, Y., Wang, A., Pei, J., .. W Wang, Y. (2019). Rhodiola species: A comprehensive review of traditional use, phytochemistry, pharmacology, toxicity, and clinical study. Medicinal Research Reviews, 39 (5), 1779-1850. doi:10.1002/med.21564

Tay, M. Z., Poh, C. M., Renia, L., MacAry, P. A., \& Ng, L. F. P. (2020). The trinity of COVID-19: immunity, inflammation and intervention. Nat Rev Immunol, 20 (6), 363-374. doi:10.1038/s41577-020-03118

Teplyakova, T. V., \& Kosogova, T. A. (2016). Antiviral Effect of Agaricomycetes Mushrooms (Review). Int J Med Mushrooms, 18 (5), 375-386. doi:10.1615/intjmedmushrooms.v18.i5.10

Teuscher, E., Willuhn, G., \& Loew, D. (2016). Sambuci fructus. In W. Blaschek (Ed.), Wichtl - Teedrogen und Phytopharmaka (pp. 586-588). Stuttgart: Wissenschaftliche Verlagsgesellschaft mbH.

Thale, C., Kiderlen, A. F., \& Kolodziej, H. (2011). Anti-infective activities of Pelargonium sidoides (EPS (R) 7630): effects of induced NO production on Leishmania major in infected macrophages and antiviral effects as assessed in a fibroblast-virus protection assay. Planta Med, 77 (7), 718-725. doi:10.1055/s-0030-1250567

Timmer, A., Gunther, J., Motschall, E., Rucker, G., Antes, G., \& Kern, W. V. (2013). Pelargonium sidoides extract for treating acute respiratory tract infections. Cochrane Database Syst Rev (10), CD006323. doi:10.1002/14651858.CD006323.pub3

Todd, D. A., Gulledge, T. V., Britton, E. R., Oberhofer, M., Leyte-Lugo, M., Moody, A. N., ... Cech, N. B. (2015). Ethanolic Echinacea purpurea Extracts Contain a Mixture of Cytokine-Suppressive and CytokineInducing Compounds, Including Some That Originate from Endophytic Bacteria. PLOS ONE, 10 (5), e0124276. doi:10.1371/journal.pone.0124276

Torabian, G., Valtchev, P., Adil, Q., \& Dehghani, F. (2019). Anti-influenza activity of elderberry (Sambucus nigra). Journal of Functional Foods, 54, 353-360.

Ulbricht, C., Basch, E., Cheung, L., Goldberg, H., Hammerness, P., Isaac, R., ... Varghese, M. (2014). An evidence-based systematic review of elderberry and elderflower (Sambucus nigra) by the Natural Standard Research Collaboration. Journal of dietary supplements, 11 (1), 80-120.

Umar, S., Umar, K., Sarwar, A. H., Khan, A., Ahmad, N., Ahmad, S., . . Khan, H. A. (2014). Boswellia serrata extract attenuates inflammatory mediators and oxidative stress in collagen induced arthritis. Phytomedicine, 21 (6), 847-856. doi:10.1016/j.phymed.2014.02.001

van Haren, F. M. P., Page, C., Laffey, J. G., Artigas, A., Camprubi-Rimblas, M., Nunes, Q., .. . Dixon, B. (2020). Nebulised heparin as a treatment for COVID-19: scientific rationale and a call for randomised evidence. Crit Care, 24 (1), 454. doi:10.1186/s13054-020-03148-2 
Vardhan, S., \& Sahoo, S. K. (2020). In silico ADMET and molecular docking study on searching potential inhibitors from limonoids and triterpenoids for COVID-19. Computers in Biology and Medicine, 124, 103936. doi:https://doi.org/10.1016/i.compbiomed.2020.103936

Voldvik, V. (2015). Effekt av svarthyllbær (Sambucus nigra) og dets innholdsstoffer på in vitro modulering av NF-kappaB-aktivitet. Norwegian University of Life Sciences, Ås,

Wagner, H., Norr, H., \& Winterhoff, H. (1994). Plant adaptogens. Phytomedicine, 1 (1), 63-76. doi:10.1016/S0944-7113 (11)80025-5

Waknine-Grinberg, J. H., El-On, J., Barak, V., Barenholz, Y., \& Golenser, J. (2009). The immunomodulatory effect of Sambucol on leishmanial and malarial infections. Planta Med, 75 (6), 581-586. doi:10.1055/s-0029-1185357

Wang, X. Q., Li, H. Y., Liu, X. Y., Zhang, F. M., Li, X., Piao, Y. A., .. Li, X. (2006). [The anti-respiratory syncytial virus effect of active compound of Glycyrrhiza GD4 in vitro]. Zhong yao cai = Zhongyaocai = Journal of Chinese medicinal materials, 29 (7), 692-694.

Wasser, S. P. (2010). Medicinal mushroom science: history, current status, future trends, and unsolved problems. International Journal of Medicinal Mushrooms, 12 (1), 1-16.

Wasser, S. P. (2017). Medicinal Mushrooms in Human Clinical Studies. Part I. Anticancer, Oncoimmunological, and Immunomodulatory Activities: A Review. Int J Med Mushrooms, 19 (4), 279-317. doi:10.1615/IntJMedMushrooms.v19.i4.10

Wesa, K. M., Cunningham-Rundles, S., Klimek, V. M., Vertosick, E., Coleton, M. I., Yeung, K. S., . . Cassileth, B. R. (2015). Maitake mushroom extract in myelodysplastic syndromes (MDS): a phase II study. Cancer Immunology, Immunotherapy, 64 (2), 237-247.

Witte, K., Koch, E., Volk, H.-D., Wolk, K., \& Sabat, R. (2020). The herbal extract EPs ${ }^{\circledR} 7630$ increases the antimicrobial airway defense through monocyte-dependent induction of IL-22 in T cells. Journal of Molecular Medicine, 1-11. doi:10.1007/s00109-020-01970-3

Witte, K., Koch, E., Volk, H. D., Wolk, K., \& Sabat, R. (2015). The Pelargonium sidoides Extract EPs 7630 Drives the Innate Immune Defense by Activating Selected MAP Kinase Pathways in Human Monocytes. PLOS ONE, 10 (9), e0138075. doi:10.1371/journal.pone.0138075

Woelkart, K., \& Bauer, R. (2007). The role of alkamides as an active principle of Echinacea. Planta medica, 73 (07), 615-623.

Wrapp, D., Wang, N., Corbett, K. S., Goldsmith, J. A., Hsieh, C.-L., Abiona, O., ... McLellan, J. S. (2020). Cryo-EM structure of the 2019-nCoV spike in the prefusion conformation. Science, 367 (6483), 1260-1263.

Wu, A., Peng, Y., Huang, B., Ding, X., Wang, X., Niu, P., ... Jiang, T. (2020). Genome Composition and Divergence of the Novel Coronavirus (2019-nCoV) Originating in China. Cell Host Microbe, 27 (3), 325-328. doi:10.1016/j.chom.2020.02.001

Wu, F., Zhao, S., Yu, B., Chen, Y. M., Wang, W., Song, Z. G., ... Zhang, Y. Z. (2020). A new coronavirus associated with human respiratory disease in China. Nature, 579 (7798), 265-269. doi:10.1038/s41586-020-2008-3

Wu, J. M., Doonan, B. B., Hsieh, T. C., Yang, Q., Yang, X. T., \& Ling, M. T. (2016). Recent Advances and Challenges in Studies of Control of Cancer Stem Cells and the Gut Microbiome by the TrametesDerived Polysaccharopeptide PSP (Review). Int J Med Mushrooms, 18 (8), 651-660. doi:10.1615/IntJMedMushrooms.v18.i8.10

Wu, T. Y., Khor, T. O., Saw, C. L., Loh, S. C., Chen, A. I., Lim, S. S., ... Kong, A. N. (2011). Antiinflammatory/Anti-oxidative stress activities and differential regulation of Nrf2-mediated genes by non-polar fractions of tea Chrysanthemum zawadskii and licorice Glycyrrhiza uralensis. AAPS J, 13 (1), 1-13. doi:10.1208/s12248-010-9239-4

Xie, Y. C., Dong, X. W., Wu, X. M., Yan, X. F., \& Xie, Q. M. (2009). Inhibitory effects of flavonoids extracted from licorice on lipopolysaccharide-induced acute pulmonary inflammation in mice. Int Immunopharmacol, 9 (2), 194-200. doi:10.1016/j.intimp.2008.11.004

Yang, R., Wang, L. Q., Yuan, B. C., \& Liu, Y. (2015). The Pharmacological Activities of Licorice. Planta Med, 81 (18), 1654-1669. doi:10.1055/s-0035-1557893 
Yang, Y. (2020). Use of herbal drugs to treat COVID-19 should be with caution. Lancet, 395 (10238), 16891690. doi:10.1016/s0140-6736 (20)31143-0

Ye, Q., Wang, B., \& Mao, J. (2020). The pathogenesis and treatment of theCytokine Storm'in COVID-19. Journal of infection, 80 (6), 607-613.

Yin, Y., \& Wunderink, R. G. (2018). MERS, SARS and other coronaviruses as causes of pneumonia. Respirology, 23 (2), 130-137.

Yu, L., Qin, Y., Wang, Q., Zhang, L., Liu, Y., Wang, T., ... Xiong, H. (2014). The efficacy and safety of Chinese herbal medicine, Rhodiola formulation in treating ischemic heart disease: a systematic review and meta-analysis of randomized controlled trials. Complement Ther Med, 22 (4), 814-825. doi:10.1016/j.ctim.2014.05.001

Yu, X., Zheng, H., Qian, X., Jiang, P., \& Wang, W. (2019). Clinical efficacy of a series of chinese herbal medicines in the treatment of stable chronic obstructive pulmonary disease based on syndrome differentiation. Journal of biological regulators and homeostatic agents, 33 (5), 1539-1544.

Zahedipour, F., Hosseini, S. A., Sathyapalan, T., Majeed, M., Jamialahmadi, T., Al-Rasadi, K., ... Sahebkar, A. (2020). Potential effects of curcumin in the treatment of COVID-19 infection. Phytother Res. doi:10.1002/ptr.6738

Zakay-Rones, Z., Varsano, N., Zlotnik, M., Manor, O., Regev, L., Schlesinger, M., \& Mumcuoglu, M. (1995). Inhibition of several strains of influenza virus in vitro and reduction of symptoms by an elderberry extract (Sambucus nigra L.) during an outbreak of influenza B Panama. The Journal of Alternative and Complementary Medicine, 1 (4), 361-369.

Zhang, D. H., Wu, K. L., Zhang, X., Deng, S. Q., \& Peng, B. (2020). In silico screening of Chinese herbal medicines with the potential to directly inhibit 2019 novel coronavirus. J Integr Med, 18 (2), 152158. doi:10.1016/j.joim.2020.02.005

Zhou, F., Yu, T., Du, R., Fan, G., Liu, Y., Liu, Z., . . Cao, B. (2020). Clinical course and risk factors for mortality of adult inpatients with COVID-19 in Wuhan, China: a retrospective cohort study. Lancet, 395 (10229), 1054-1062. doi:10.1016/S0140-6736 (20)30566-3

Zhou, H., Fang, Y., Xu, T., Ni, W.-J., Shen, A.-Z., \& Meng, X.-M. (2020). Potential therapeutic targets and promising drugs for combating SARS-CoV-2. British Journal of Pharmacology, 177 (14), 3147-3161. doi:10.1111/bph.15092

Zhu, N., Zhang, D., Wang, W., Li, X., Yang, B., Song, J., ... Research, T. (2020). A Novel Coronavirus from Patients with Pneumonia in China, 2019. N Engl J Med, 382 (8), 727-733. doi:10.1056/NEJMoa2001017

Zimmermann-Klemd, A. M., Reinhardt, J. K., Nilsu, T., Morath, A., Falanga, C. M., Schamel, W. W., ... Grundemann, C. (2020). Boswellia carteri extract and 3-0-acetyl-alpha-boswellic acid suppress T cell function. Fitoterapia, 146, 104694. doi:10.1016/j.fitote.2020.104694

Zmitrovich, I. V., Belova, N. V., Balandaykin, M. E., Bondartseva, M. A., \& Wasser, S. P. (2019). Cancer without pharmacological illusions and a niche for mycotherapy. International Journal of Medicinal Mushrooms, 21 (2), 105-119. 